\title{
Advances in the synthesis and structure of $\alpha$-canaphite: a multitool and multiscale study
}

Laëtitia Mayen ${ }^{\mathrm{a}}$, Nicholai D. Jensen ${ }^{\mathrm{b}, \mathrm{c}}$, Maximilien Desbord ${ }^{\mathrm{a}}$, Danielle Laurencin ${ }^{\mathrm{b}}$, Christel Gervais ${ }^{\mathrm{c}}$, Christian Bonhomme ${ }^{\mathrm{c}}$, Mark E. Smith ${ }^{\mathrm{d}, \mathrm{e}}$ Florence Porcher ${ }^{\mathrm{f}}$, Erik Elkaim ${ }^{\mathrm{g}}$, Cédric Charvillat $^{\mathrm{a}}$, Pierre Gras ${ }^{\mathrm{a}}$, Christian Rey ${ }^{\mathrm{a}}$, Jérémy Souliéa ${ }^{\text {, Christèle Combes }}{ }^{\mathrm{a}, *}$

${ }^{a}$ CIRIMAT, Université de Toulouse, CNRS, Toulouse INP - ENSIACET, Toulouse, France bICGM, CNRS-UM-ENSCM, Université de Montpellier, Montpellier, France

'Sorbonne Université, CNRS, Laboratoire de Chimie de la Matière Condensée de Paris, UMR 7574, 4 place Jussieu, 75252 Paris, France

${ }^{\mathrm{d}}$ Vice-Chancellor's Office, Highfield Campus, University of Southampton, University Road, Southampton, SO17 1BJ, University of Southampton, UK, and Department of Chemistry, Lancaster University, Bailrigg, Lancaster, LA1 4YB, UK

eDepartment of Physics, University of Warwick, Coventry, UK

${ }^{\mathrm{f}}$ Laboratoire Léon Brillouin, CEA Saclay, Gif-sur-Yvette, France

'Synchrotron Soleil, L’Orme les Merisiers, St Aubin, Gif-sur-Yvette, France

*Corresponding author.

E-mail address: christele.combes@ensiacet.fr

Keywords: Canaphite, Calcium pyrophosphates, Synthesis, Synchrotron X-ray and neutron diffraction, Structure refinement, DFT, NMR, dehydration 


\begin{abstract}
$\alpha$-canaphite $\left(\mathrm{CaNa}_{2} \mathrm{P}_{2} \mathrm{O}_{7} .4 \mathrm{H}_{2} \mathrm{O}\right)$ is a layered calcium disodium pyrophosphate tetrahydrate phase of significant geological and potential of biological interest. This study overcome the lack of a reliable protocol to synthesize pure $\alpha$-canaphite by using a novel simple and reproducible approach of double decomposition in solution at room temperature. The pure $\alpha$-canaphite is then characterised from the atomic to the macroscopic level using a multitool and multiscale advanced characterization strategy, providing for the first time full resolution of the $\alpha$-canaphite monoclinic structure, including the hydrogen bonding network. Synchrotron X-ray and neutron diffraction are combined with multinuclear solid state NMR experimental data and computational modeling via DFT/GIPAW calculations. Among the main characteristics of the $\alpha$-canaphite structure are some strong hydrogen bonds and one of the four water molecules showing a different coordination schema. This peculiar water molecule could be the last to leave the collapsed structure on heating, leading eventually to anhydrous $\alpha-\mathrm{CaNa}_{2} \mathrm{P}_{2} \mathrm{O}_{7}$ and could also be involved in the internal hydrolysis of pyrophosphate ions as it is the closest water molecule to pyrophosphate ions. Relating such detailed structural data on $\alpha$-canaphite to its physico-chemical properties are of major interest considering the possible roles of canaphite for biomedical applications. The vibrational spectra of $\alpha$-canaphite (deuterated or not) are analyzed and Raman spectroscopy appears to be a promising tool for the identification/diagnosis of such microcrystals in vitro, in vivo or ex vivo.
\end{abstract}




\section{Introduction}

Condensed phosphate structures have received much less attention than orthophosphate ones. All polyphosphates are indeed hydrolyzed in aqueous solutions, and it has long been considered that this hydrolytic degradation was the cause of the quasi-absence of polyphosphate geological minerals. Pyrophosphates (i.e. diphosphates $\mathrm{P}_{2} \mathrm{O}_{7}{ }^{4-}$ ) are the most stable polyphosphate anions, and interestingly, hydrated calcium pyrophosphate salts are encountered in both geological and biological environments. ${ }^{1-}$

${ }^{3}$ In the field of geological minerals, the calcium disodium pyrophosphate tetrahydrate, also called canaphite $\left(\mathrm{CaNa}_{2} \mathrm{P}_{2} \mathrm{O}_{7} \cdot 4 \mathrm{H}_{2} \mathrm{O}\right)$, has been identified as the first example of condensed phosphate geological mineral. ${ }^{2}$ The only forms of persistent polyphosphates identified in a biological extracellular medium are the calcium pyrophosphate dihydrates $\mathrm{Ca}_{2} \mathrm{P}_{2} \mathrm{O}_{7} \cdot 2 \mathrm{H}_{2} \mathrm{O}$ (monoclinic and triclinic, m-CPPD and t-CPPD respectively), which occur in joints of patients suffering from pseudogout. ${ }^{4-5}$ Pritzker et al. ${ }^{6}$ also reported the possible formation of canaphite in vitro after $24 \mathrm{~h}$ at $10^{\circ} \mathrm{C}$ or $37^{\circ} \mathrm{C}$ in a crystallization model system involving sodium pyrophosphate and calcium chloride diffusion in cadaveric articular hyaline cartilage (raw or denaturated). Moreover, Mandel et al. ${ }^{7}$ studied the in vitro modeling of mCPPD and t-CPPD crystal deposition, and their results revealed the formation of $\alpha$ and $\beta$-canaphite crystals as minor phases in a biological grade gelatin gel at physiological $\mathrm{pH}$.

Few studies related to canaphite have been published so far. Two polymorphs of canaphite, namely $\alpha$ and $\beta$ have been identified as monoclinic structures and the $\gamma$ polymorph structure remains unknown. ${ }^{2,8}$ Cheng et al. ${ }^{9}$ obtained the $\beta$-canaphite phase by diffusion of solutions in hydrogel-like media mimicking the synovial fluids, and they were able to determine its crystal structure. Subsequently, Cheng and Pritzker $^{8}$ synthesized the $\alpha$-canaphite phase at room temperature by adding a sodium pyrophosphate solution at neutral $\mathrm{pH}$ into a calcium salt solution. They showed that this $\alpha$ phase crystallized in the monoclinic system with Pc space group, but the positions of hydrogen atoms were not determined. Later, Rouse et $a .^{2}{ }^{2}$ confirmed this monoclinic structure and reported extensive interatomic distances and angles data, making a comparison to the data from Cheng and Pritzker. ${ }^{8}$ The hydrogen atom positions were still missing.

Following these initial studies, Cave ${ }^{10}$ synthesized $\alpha$-canaphite according to a modified protocol from Cheng and Pritzker. ${ }^{8}$ This involved pouring-together cationic and anionic solutions whereupon precipitation occurred without the need of neutralizing the pyrophosphate solution. The precipitate was then matured overnight. Examination of the XRD pattern presented suggested that an amorphous phase might be present in the as-synthesized $\alpha$-canaphite sample. This observation is supported by the estimated number of structural water molecules from thermogravimetric analysis (3.5 per formula unit) as this is not consistent with the stoichiometry of pure $\alpha$-canaphite. Another method claimed $\alpha$-canaphite could be prepared by mechanical grinding of a mixture of precursor salts for several hours in the presence of water, leading to a fairly pure phase, containing $5 \% \mathrm{w} / \mathrm{w}$ of impurities. ${ }^{11} \alpha$ and $\beta$ canaphite both possess a layered structure which could confer specific dehydration and ion exchange properties to these compounds. The sodium ions exchangeability in canaphite was successfully 
investigated by reflux reaction of canaphite for two hours in potassium nitrate saturated solution leading to anhydrous potassium pyrophosphate phase following a structural rearrangement. ${ }^{10}$

A FTIR and Raman vibrational spectroscopic study of synthetic $\alpha$-canaphite did not present evidence of sample purity. ${ }^{12}$ To the best of our knowledge, no solid state NMR studies of canaphite polymorphs have been reported so far, in contrast to other crystalline calcium pyrophosphate phases, which have been studied by ${ }^{1} \mathrm{H},{ }^{31} \mathrm{P}$ and ${ }^{43} \mathrm{Ca}$ magic angle spinning (MAS) solid state NMR techniques. ${ }^{13-16}$

A small number of papers concerning canaphite to date have all referred to the synthesis protocol by Cheng and Pritzker ${ }^{8}$, with some adaptations. However, both the protocol and its modifications are poorly described in the literature. In addition, the synthetic canaphite samples were not fully characterized to check for their purity before further structural investigations.

Considering the potential development of canaphite-based biomaterials and/or canaphite identification/diagnosis in the biomedical field, it is essential to thoroughly study its structure. Thus will allow better understanding of disease associated with calcium pyrophosphate-based crystal deposition and the related material properties. In addition it will allow the potential of such a compound as an innovative bioactive bone substitute material based on enzyme- and/or pH-driven pyrophosphate $\left(\mathrm{P}_{2} \mathrm{O}_{7}{ }^{4-}\right)$ hydrolysis into orthophosphate $\left(\mathrm{PO}_{4}{ }^{3-}\right)$ to be better understood. ${ }^{17}$ In this context the present study initially described a robust protocol for the synthesis of pure $\alpha$-canaphite. Then an advanced multiscale characterization methodology combining synchrotron and laboratory experimental techniques and computational modeling tools is applied to thoroughly characterize the phase from the atomic to the macroscopic scales. This provides a full solution of crystal structure, including the positions of hydrogen atoms.

\section{Materials and Methods}

\section{Precursors}

Calcium chloride dihydrate salt $\left(\mathrm{CaCl}_{2} .2 \mathrm{H}_{2} \mathrm{O}, 100.2 \%\right.$, VWR Chemicals) was used as received. The pyrophosphate precursor, anhydrous tetrasodium pyrophosphate $\left(\mathrm{Na}_{4} \mathrm{P}_{2} \mathrm{O}_{7}\right)$, was prepared by heating disodium hydrogen phosphate $\left(\mathrm{Na}_{2} \mathrm{HPO}_{4}, 99 \%\right.$, Merck) at $400^{\circ} \mathrm{C}$ during 15 hours in a muffle furnace. The purity of the as-prepared sodium pyrophosphate precursor was checked by XRD, Raman and ${ }^{31} \mathrm{P}$ solid state NMR spectroscopies (no residual orthophosphate was detected, Figure S1) before its use for $\alpha$-canaphite synthesis.

\section{$\alpha$-canaphite synthesis}

$\alpha$-canaphite powder was synthesized by double decomposition in solution (precipitation) at room temperature using an original protocol. Calcium and phosphate reagent solutions were prepared separately by dissolving $2.11 \mathrm{~g}$ of $\mathrm{CaCl}_{2} \cdot 2 \mathrm{H}_{2} \mathrm{O}(0.0144 \mathrm{~mole})$ in $80 \mathrm{~mL}$ of deionized water, and $17.71 \mathrm{~g}$ of the as-prepared sodium pyrophosphate $\left(\mathrm{Na}_{4} \mathrm{P}_{2} \mathrm{O}_{7}\right)$ precursor $(0.0666$ mole) in $800 \mathrm{~mL}$ of deionized water. The calcium solution was then added to the pyrophosphate solution at a constant volumetric flowrate (32 $\mathrm{mL} \cdot \mathrm{min}^{-1}$ ) using a peristaltic pump. After complete addition, the suspension was left to 
mature for 24 hours under magnetic stirring, and then filtrated, and washed with $800 \mathrm{~mL}$ of deionized water. The precipitate was finally dried at $37^{\circ} \mathrm{C}$ during one night and then stored at $-20^{\circ} \mathrm{C}$ to prevent for any structural evolution before characterization. This synthesis has been performed at least in triplicate to check for its reproducibility.

In view of the fine structural study by neutron diffraction and the FTIR and Raman band assignments, deuterated canaphite was prepared following the protocol detailed above, but using deuterated water $\left(\mathrm{D}_{2} \mathrm{O}\right.$, Sigma Aldrich, Deuterium Oxide 99 atom\% D) instead of deionized water to prepare both precursor solutions and as washing medium after filtration. In addition, several precautions were taken at each step of the synthesis protocol to prevent as much as possible any deuterium-hydrogen exchange with water vapor present in the air during powder transfers and storage (hermetically sealed flasks, drying by lyophilization, storage first in a dessicator with a deuterated water saturated atmosphere). Finally, the sample was vacuum-packed in a plastic bag and stored in the freezer before its analysis.

\section{$\alpha$-canaphite characterizations}

The as-synthesized $\alpha$-canaphite powder was fully characterized using complementary multiscale laboratory and synchrotron and neutron techniques for structural, microstructural, molecular and elemental investigations, in combination with computational DFT modeling tools.

Powder $X$-ray diffraction $(X R D)$. A preliminary XRD analysis was performed at room temperature using a laboratory X-ray diffractometer (INEL Symphonix 1000) with a cobalt anticathode $\left(\lambda\left(\mathrm{K}_{\alpha}\right)=1.788970\right.$ $\AA$ ) and a curved counter to rapidly check the sample purity. Then the as-synthesized $\alpha$-canaphite powder was further analyzed on a synchrotron facility to collect data for structure refinement. Synchrotron powder X-ray diffraction patterns of the synthesized $\alpha$-canaphite were acquired at $21^{\circ} \mathrm{C}$ on the twocircle diffractometer of the CRISTAL beamline at the SOLEIL synchrotron (Gif-sur-Yvette, France) as part of the project No. 20130932 "Structural investigations on hydrated calcium pyrophosphate phases of biological interest: study on synthetic and biological samples". A monochromatic beam was selected, using a Si (111) double-crystal monochromator, and its wavelength (0.5815 $\AA$ ) was determined using NIST standard $\mathrm{LaB}_{6}$. The powder sample was placed in a $0.7 \mathrm{~mm}$-diameter special glass capillary mounted on a spinner to improve averaging. High angular resolution was obtained with the 21 perfect Si (111) crystal rear analyzer mounted on a two-circle diffractometer. Detection was performed using Scionix YAP: Ce scintillation detectors.

Neutron diffraction analysis. In order to locate precisely the $\mathrm{D}$ atoms, neutron powder diffraction (NPD) measurements were performed on the synthesized deuterated $\alpha$-canaphite. The experiment was carried out at the G44 diffractometer on the S2 cold source at the Orphée-LLB reactor (France). The diffractogram was recorded at $233 \mathrm{~K}$ using a Ge004 monochromator at a neutron wavelength of 1.959 $\AA$ between $2 \theta=6.00^{\circ}$ and $161.30^{\circ}$ with steps of $0.05^{\circ}$. Between $149.00^{\circ}<2 \theta<152.00^{\circ}$ the cryofurnace used gave rise to a parasitic peak and this zone had to be excluded from subsequent analyses. 
Structure refinements. D atoms were located from difference Fourier maps calculated with the NPD data. Subsequent Rietveld refinements were performed using the JANA 2006 software from joint NPD and synchrotron XRD data. Because this procedure imposed a common value of the cell parameters for the two set of measurements (synchrotron X-ray and neutron diffraction measurements), both wavelengths were refined in order to absorb potential discrepancies in peaks positions; the refined values remained close to the initial values. Distance (H-O distances within $0.001 \AA$ ), angle restraints $(\mathrm{H}-\mathrm{O}-\mathrm{H}$ $\left.=104.45(1)^{\circ}\right)$ and equivalence between all isotropic thermal displacement parameters were imposed for the refinement of the water molecules. All the representations of the refined structure presented in this paper were obtained using Vesta. ${ }^{18}$

FTIR and Raman vibrational spectroscopic analysis. A Raman Labram HR 800 confocal microscope Horiba Yvon Jobin and a laser radiation provided by a $532 \mathrm{~nm}$ Argon diode laser with a power of 14 $\mathrm{mW}$ were used. Each spectrum was acquired with an integration time of 60 seconds and three accumulations. FTIR spectra were obtained using a Nicolet IS50 FT-IR spectrophotometer (Thermo Scientific) at $4 \mathrm{~cm}^{-1}$ resolution and 64 scan accumulation, by transmission from a $\mathrm{KBr}$ pellet. $\alpha$-canaphite and it deuterated analogue were both analyzed by FTIR and Raman spectroscopy.

Scanning Electron Microscopy (SEM). SEM observations were performed on a LEO 435 VP microscope. Samples were stuck on double-faced carbon tape and silver sputter-coated before observation.

Thermal analyses. Thermogravimetric (TGA) and differential thermal analysis (DTA) were performed in triplicate using a Setaram instrument (Setsys Evolution System) from $20^{\circ} \mathrm{C}$ to $1000^{\circ} \mathrm{C}$ with a step of $30 \mathrm{~min}$ at $1000^{\circ} \mathrm{C}$, and a heating rate of $4^{\circ} \mathrm{C}$ per minute in air flow.

Inductively Coupled Plasma - Optical Emission Spectrometry (ICP-OES). The analyses were performed on an ICP Ultima Expert machine (argon flow: $15 \mathrm{~L} / \mathrm{min}$ ) to determine the calcium, phosphorus and sodium concentrations in triplicate.

Ultra-High Pressure phase Liquid Chromatography (UHPLC). A Waters Acquity apparatus coupled with an evaporative light scattering detector (ELSD) was used for the detection and titration of traces of chloride ions. Measurements were done in triplicate.

Solid state NMR. The experiments were performed on the non-deuterated $\alpha$-canaphite samples to analyze the local environments of ${ }^{23} \mathrm{Na},{ }^{31} \mathrm{P},{ }^{43} \mathrm{Ca}$ and ${ }^{1} \mathrm{H}$ nuclei. All solid state NMR spectra were recorded at $14.1 \mathrm{~T}$ on a VNMRS-600 $\mathrm{MHz}$ spectrometer, except for ${ }^{1} \mathrm{H}$ NMR experiments, which were recorded at 20.0 T on a Bruker $850 \mathrm{MHz}$ NMR spectrometer (NEO 4 console). A ${ }^{1} \mathrm{H}$ spin-echo NMR spectrum was acquired using a $1.3 \mathrm{~mm} \mathrm{HXY}$ MAS probe tuned to ${ }^{1} \mathrm{H}\left(v_{0}=850.23 \mathrm{MHz}\right)$. The experiment was performed at $40 \mathrm{kHz}$ MAS. The spectra were recorded using a $2.1 \mu \mathrm{s} 90^{\circ}$ and $4.2 \mu \mathrm{s} 180^{\circ}{ }^{1} \mathrm{H}$ pulse, with 1 rotor period echo delay, and using $2 \mathrm{~s}$ recycle delay. A total of 16 scans were collected. The experiments were performed with the temperature control unit set to $-10{ }^{\circ} \mathrm{C}$. ${ }^{1} \mathrm{H}$ chemical shifts were referenced to the methyl groups in alanine $\left(\delta_{\text {iso }}\left({ }^{1} \mathrm{H}\right)=1.20 \mathrm{ppm}\right)$. A ${ }^{31} \mathrm{P}$ single pulse experiment was performed using a $3.2 \mathrm{~mm}$ HXY MAS probe tuned to ${ }^{1} \mathrm{H}\left(v_{0}=599.82 \mathrm{MHz}\right)$ and ${ }^{31} \mathrm{P}\left(v_{0}=242.81 \mathrm{MHz}\right)$, and spinning at $18 \mathrm{kHz}$. A $3 \mu \mathrm{s} 90^{\circ}$ excitation pulse was used (RF $\left.\approx 83 \mathrm{kHz}\right)$, and spinal-64 ${ }^{1} \mathrm{H}$ 
decoupling $(\mathrm{RF}=100 \mathrm{kHz})$ during acquisition. A recycle delay of $800 \mathrm{~s}$ was used for full relaxation, and 24 scans were collected. ${ }^{31} \mathrm{P}$ chemical shifts were referenced to the phosphate group in synthetic hydroxyapatite, $\mathrm{Ca}_{10}\left(\mathrm{PO}_{4}\right)_{6}(\mathrm{OH})_{2}\left(\delta_{\text {iso }}\left({ }^{31} \mathrm{P}\right)=2.8 \mathrm{ppm}\right)$. A ${ }^{23} \mathrm{Na}$ single pulse MAS NMR spectrum was recorded using a $3.2 \mathrm{~mm}$ HXY MAS probe spinning at $20 \mathrm{kHz}$, and the temperature control unit set to $0{ }^{\circ} \mathrm{C}$. The experiment was performed using a $0.5 \mu \mathrm{s} 30^{\circ}{ }^{23} \mathrm{Na}$ solid pulse (RF $\approx 83 \mathrm{kHz}$ ) and spinal-64 ${ }^{1} \mathrm{H}$ decoupling $(\mathrm{RF} \approx 100 \mathrm{kHz}$ ) during acquisition. A 1 s recycle delay was used, and 6000 scans were collected. The ${ }^{23} \mathrm{Na} \mathrm{NMR}$ chemical shifts were referenced to a $1.0 \mathrm{M} \mathrm{NaCl}$ aqueous solution $\left(\delta_{\text {iso }}\left({ }^{23} \mathrm{Na}\right)\right.$ $=0 \mathrm{ppm}) . \mathrm{A}^{43} \mathrm{Ca}$ MAS NMR spectrum was recorded using a $9.5 \mathrm{~mm}$ probe, spinning at $4 \mathrm{kHz}$. A $3 \mu \mathrm{s}$ ${ }^{43} \mathrm{Ca}$ excitation pulse was used $\left(30^{\circ}\right.$ solid pulse, $\left.\mathrm{RF} \approx 15 \mathrm{kHz}\right)$, preceded by a DFS pulse of $4 \mathrm{~ms}$, with a DFS sweep from $250 \mathrm{kHz}$ to $60 \mathrm{kHz}$ in order to increase sensitivity. The spectrum was recorded using a 5 s recycle delay and 31700 scans were co-added. The chemical shifts were referenced to a $1 \mathrm{M} \mathrm{CaCl}_{2}$ aqueous solution $\left(\delta_{\text {iso }}\left({ }^{43} \mathrm{Ca}\right)=0 \mathrm{ppm}\right)$, while powers were calibrated on a saturated $\mathrm{CaCl}_{2}$ solution. No temperature control was applied.

Computational study. The unit cell parameters were set to the combined neutron/synchrotron X-ray diffraction data and kept fixed during geometry optimizations to ensure consistency between experimental and optimized structures. Atomic positions were then relaxed with the VASP (Vienna Abinitio Simulation Package) code ${ }^{19}$ based on the Kohn-Sham Density Functional Theory (DFT) and using a plane-wave pseudopotential approach. Two situations were tested: relaxing $\mathrm{H}$ positions only, or all atomic positions. The NMR parameters were then calculated within Kohn-Sham DFT using the QUANTUM-ESPRESSO code $^{20-21}$, keeping the atomic positions equal to the values previously calculated with VASP. The PBE generalized gradient approximation ${ }^{22}$ was used and the valence electrons were described by norm conserving pseudopotentials ${ }^{23}$ in the Kleinman Bylander form. ${ }^{24}$ The shielding tensor was computed using the Gauge Including Projector Augmented Wave (GIPAW) approach $^{25}$, which enables the reproduction of the results of a fully converged all electron calculation ${ }^{26}$. The isotropic chemical shift $\delta_{\text {iso }}$ is defined as $\delta_{\text {iso }}=-\left[\sigma-\sigma_{\text {ref }}\right]$ where $\sigma$ is the isotropic shielding and $\sigma_{\text {ref }}$ is the isotropic shielding of the same nucleus in a reference system. $\sigma_{\text {ref }}$ was fixed so that the average sum of experimental and calculated shifts of a series of reference compounds coincide, typically calcium phosphates and pyrophosphates for ${ }^{31} \mathrm{P}$ and ${ }^{43} \mathrm{Ca},{ }^{27}$ and sodium phosphates and silicates for ${ }^{23} \mathrm{Na}$. The principal components $V_{x x}, V_{y y}$, and $V_{z z}$ of the electric field gradient (EFG) tensor defined as $\left|V_{z z}\right| \geq\left|V_{x x}\right|$ $\geq\left|V_{y y}\right|$ are obtained by diagonalization of the calculated tensor. The quadrupolar interaction can then be characterized by the quadrupolar coupling constant $C_{Q}$ and the asymmetry parameter $\eta_{Q}$, which are defined as: $\mathrm{C}_{\mathrm{Q}}=\mathrm{eQV}_{\mathrm{zz}} / \mathrm{h}$ and $\eta_{\mathrm{Q}}=\left(\mathrm{V}_{\mathrm{yy}}-\mathrm{V}_{\mathrm{xx}}\right) / \mathrm{V}_{\mathrm{zz}}$ (e is the proton charge, $\mathrm{h}$ Planck's constant and $\mathrm{Q}$ the quadrupole moment of the considered nucleus). $\mathrm{Q}$ values of 104 and $-44.4 \mathrm{mb}$ were used for ${ }^{23} \mathrm{Na}$ and ${ }^{43} \mathrm{Ca}$ respectively, in agreement with the values reported by Pyykkö ${ }^{28}$ and Bryce. ${ }^{29}$ 


\section{Results and discussion}

\section{Composition of the synthesized powder}

Preliminary X-ray diffraction laboratory analysis of the as synthesized canaphite powder showed that the sample corresponds to the $\alpha$-canaphite phase according to ICSD data (n²6015) (Figure S2). The elemental composition (Ca, Na and P) of the powder was determined by ICP-OES spectrometry (Table 1). The experimental values were in agreement with the theoretical ones. In addition, attempts to detect chloride ions (counter ions from the calcium salt precursor, i.e. $\mathrm{CaCl}_{2} \cdot 2 \mathrm{H}_{2} \mathrm{O}$ ) using UHPLC were

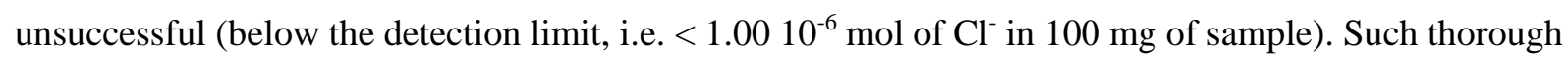
elemental characterizations which were not performed in previous published studies, are essential to further study and discuss on the related structure and properties of $\alpha$-canaphite.

Table 1: Chemical composition (Ca, $\mathrm{P}$ and $\mathrm{Na}$ amount in mmoles/100 mg of sample and $\mathrm{Ca} / \mathrm{P}$ and $\mathrm{Ca} / \mathrm{Na}$ atomic ratios) of the synthesized $\alpha$-canaphite powder determined by ICP-OES spectrometry compared with the expected values for pure canaphite.

\begin{tabular}{|c|c|c|c|c|c|}
\hline & $\begin{array}{c}\text { Ca } \\
\mathrm{mmole} / 100 \mathrm{mg}\end{array}$ & $\begin{array}{c}\mathbf{P} \\
\mathrm{mmole} / 100 \mathrm{mg}\end{array}$ & $\begin{array}{c}\text { Na } \\
\mathrm{mmole} / 100 \mathrm{mg}\end{array}$ & $\mathbf{C a} / \mathbf{P}$ & $\mathbf{C a} / \mathbf{N a}$ \\
\hline $\begin{array}{c}\text { Synthesized } \\
\text { a-canaphite }\end{array}$ & $0.298 \pm 0.002$ & $0.587 \pm 0.004$ & $0.592 \pm 0.001$ & $0.508 \pm 0.006$ & $0.503 \pm 0.003$ \\
\hline $\begin{array}{c}\text { Theoretical } \\
\text { composition }\end{array}$ & 0.301 & 0.602 & 0.602 & 0.5 & 0.5 \\
\hline
\end{tabular}

TGA analysis of the synthesized $\alpha$-canaphite showed that the mass loss, related to the water release, occurred in two steps between $\approx 70^{\circ} \mathrm{C}$ and $\approx 160^{\circ} \mathrm{C}$ (confirmed by the first derivative curve in red, Figure b). The mass loss is stabilized at $\approx 400^{\circ} \mathrm{C}$ corresponding to the total removal of water. The total mass loss reached $21.4 \pm 0.5 \%$ and allowed determining the number of water molecules associated to the assynthesized $\alpha$-canaphite: $3.92 \pm 0.09$. This value is close to that expected theoretically. The DTA analysis curve (Figure 1a) revealed the presence of an exothermic peak at about $440^{\circ} \mathrm{C}$ which corresponds to a recrystallization phenomenon. The as-synthesized $\alpha$-canaphite powder was treated at $400^{\circ} \mathrm{C}$ and $600^{\circ} \mathrm{C}$ during $15 \mathrm{~h}$ to identify the recrystallization product. The XRD analysis of both heattreated powders (at $400^{\circ} \mathrm{C}$ and $600^{\circ} \mathrm{C}$ ) revealed the formation of the same anhydrous crystalline phase: $\alpha-\mathrm{CaNa}_{2} \mathrm{P}_{2} \mathrm{O}_{7}$ (triclinic) which has been already described by Bennazha et al. ${ }^{30}$ However, a shift of the diffraction peaks leading to slightly different unit cell parameters compared to the data reported in the literature was observed (data not shown). The current refined structural data of the as-prepared $\alpha$ $\mathrm{CaNa}_{2} \mathrm{P}_{2} \mathrm{O}_{7}$ are presented in Table $\mathrm{S} 1$. The dehydration of $\alpha$-canaphite will be discussed later, after the presentation of its fine structural characterization. 
a

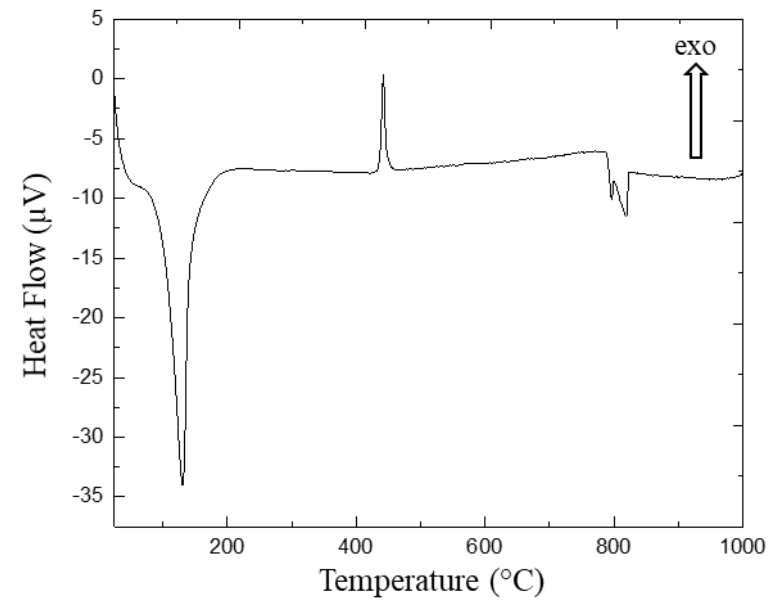

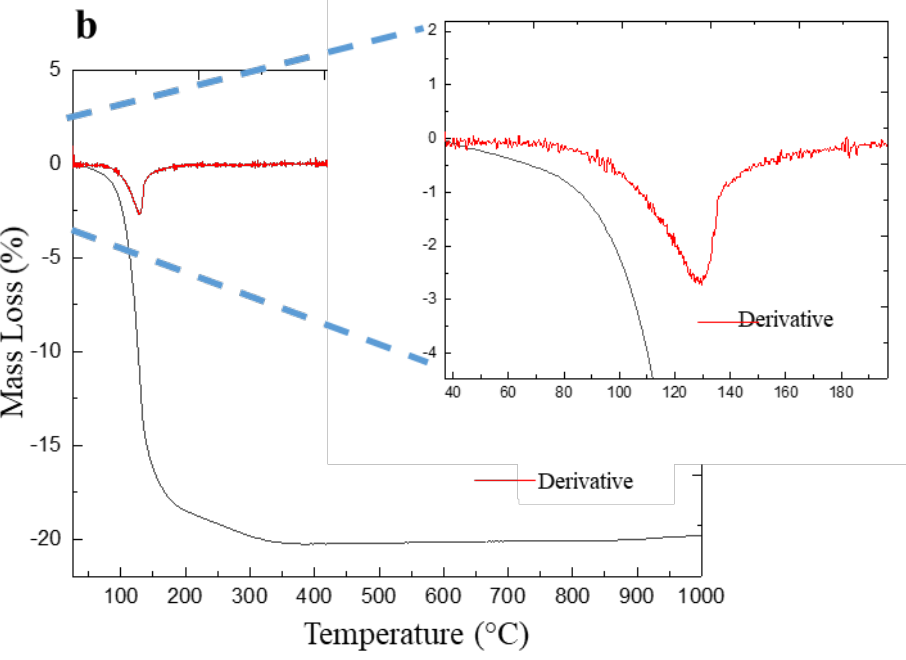

Figure 1. DTA (a) and TGA (b) curves of the synthesized $\alpha$-canaphite powder.

All together these first results demonstrated that the original protocol developed for $\alpha$-canaphite powder synthesis by double decomposition in solution at room temperature is reproducible and confirms the obtainment of $\alpha$-canaphite crystalline phase $\left(\mathrm{CaNa}_{2} \mathrm{P}_{2} \mathrm{O}_{7} .4 \mathrm{H}_{2} \mathrm{O}\right)$; the potential presence of a small amount of an amorphous compound with a calcium disodium pyrophosphate tetrahydrate composition in the synthesized sample will be checked later by solid state NMR.

\section{Morphological characterization of the synthesized $\alpha$-canaphite crystals.}

SEM was used to determine the morphology of the $\alpha$-canaphite particles (Figure 2). The particles presented a bundle-like morphology, including platelet-like crystals gathered from the middle of the bundle. The characteristic size of these platelets was approximately $11.0 \mu \mathrm{m}$ in length, $2.0 \mu \mathrm{m}$ in width and $0.1 \mu \mathrm{m}$ in thickness (Figure 2). The platelet morphology of the individual $\alpha$-canaphite crystals could be related to its layered structure. The bundle-like organization of the as-prepared $\alpha$-canaphite crystals is similar to that of natural canaphite mineral referenced in mineralogy database (for example: mindat.org). It can be hypothesized that such bundle-like crystal agglomerates result from a spherulite formation process which generally occurs when the driving force (i.e. supersaturation) is quite high or when crystals habit is highly oriented; the platelet-like morphology of $\alpha$-canaphite crystals could favor this organization as polycrystalline growth system. ${ }^{31}$ Category 1 spherulites are known to grow radially from the nucleation site whereas category 2 spherulites start to grow like thread fibers leading to a crystals sheaf after branching which finally ended as a sphere after longer evolution times. The organization of $\alpha$-canaphite platelet crystals observed by SEM (Figure 2) corresponds to a category 2 spherulites growth (Figures 2b and 2c). However it appears that some of the observed category 2 spherulites are not perfectly symmetric and some of the platelets crystals are disassembled and/or fragmented (Figure 2a); the 24h-maturation under magnetic stirring, filtration, and washing are steps for canaphite synthesis that can have altered the growth of these spherulites. The formation of category 2 
spherulites was also identified for monoclinic calcium pyrophosphate tetrahydrate (m-CPPT $\beta$ ) and dihydrate (m-CPPD) crystals formation from amorphous calcium pyrophosphate evolution in solution at $\mathrm{pH}=5.8$ and $50^{\circ} \mathrm{C} .^{32}$
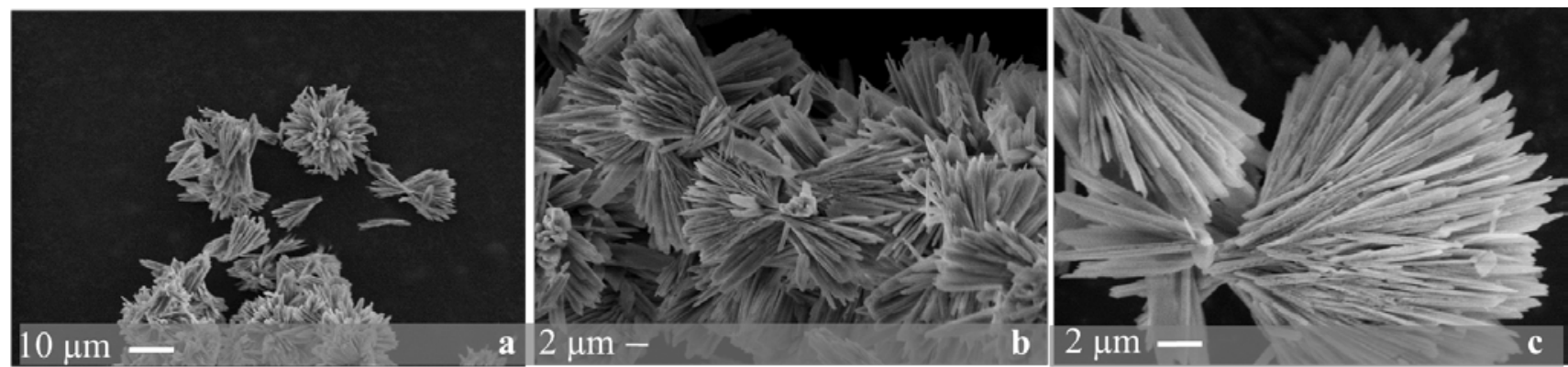

Figure 2: SEM micrographs of the synthesized $\alpha$-canaphite crystals.

Fine structural characterization of the as-synthesized $\alpha$-canaphite phas.

The as-synthesized non-deuterated and deuterated $\alpha$-canaphite samples were analyzed by synchrotron $\mathrm{X}$-ray and neutron diffraction, respectively (Figure 3). Then Rietveld refinements were performed from joint neutron and synchrotron-X-ray diffraction data (Table 2). 

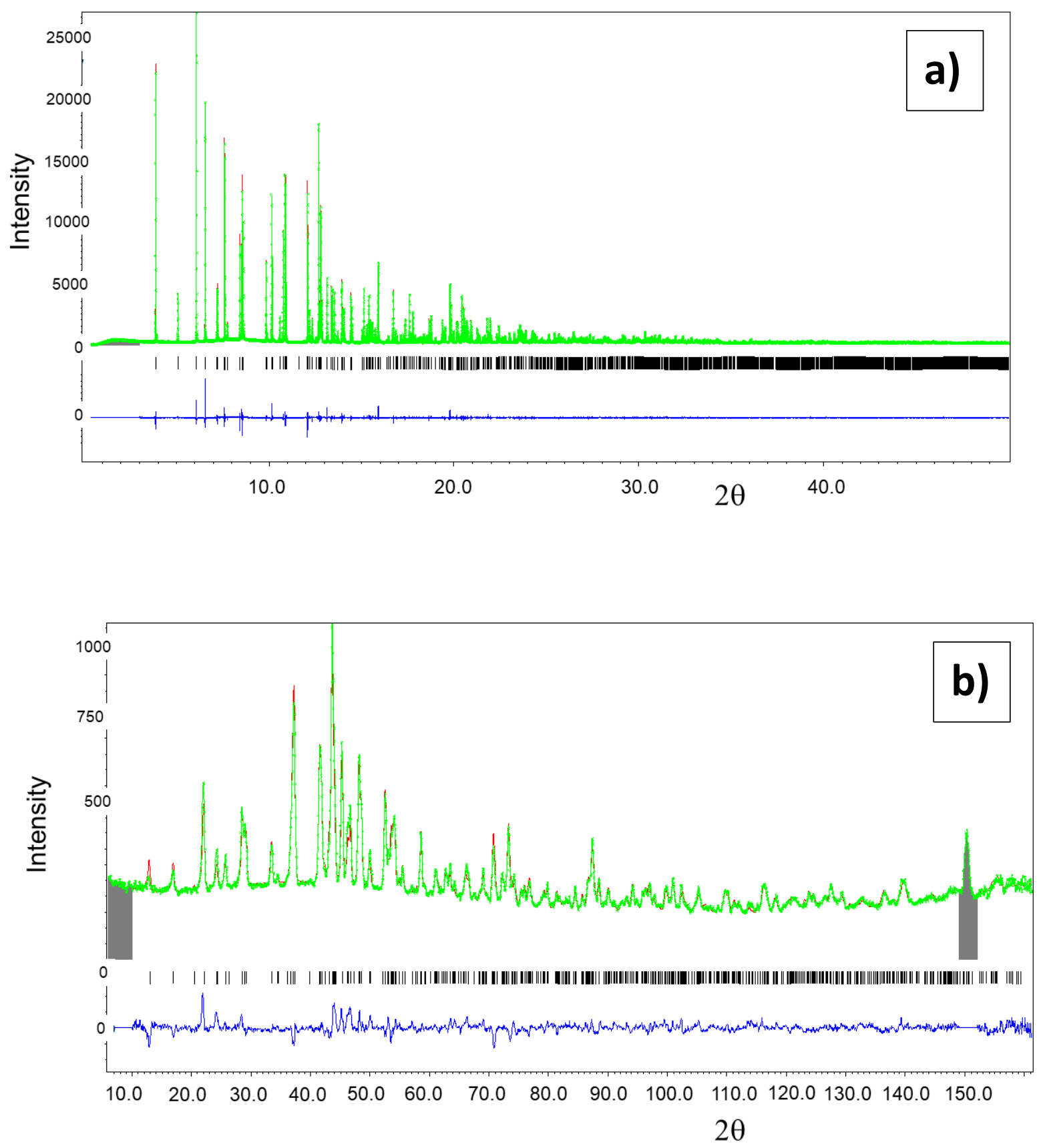

Figure 3: Rietveld refinement plots from powder synchrotron X-ray diffraction data (a) and neutron diffraction data (b) of the synthesized $\alpha$-canaphite (non-deuterated (a) and deuterated (b)). Experimental and simulated diagrams and difference are shown; vertical lines indicate the Bragg peak positions. (The grey zone around $150^{\circ}$ on neutron pattern (b) corresponds to a parasitic peak related to the cryofurnace, which is excluded for data refinement). 
Table 2: Experimental and structure refinement details of synchrotron X-ray and neutron diffraction data.

\begin{tabular}{|c|c|c|}
\hline & Synchrotron XRD & Neutron diffraction \\
\hline \multicolumn{3}{|l|}{ Crystal data } \\
\hline Chemical formula & $\mathrm{CaNa}_{2} \mathrm{P}_{2} \mathrm{O}_{7} .4 \mathrm{H}_{2} \mathrm{O}$ & $\mathrm{CaNa}_{2} \mathrm{P}_{2} \mathrm{O}_{7} .4 \mathrm{D}_{2} \mathrm{O}$ \\
\hline$M_{\mathrm{r}}$ & \multicolumn{2}{|c|}{$680.22 \mathrm{~g} / \mathrm{mol}$ (Deuterated) } \\
\hline$a, b, c(\AA)$ & \multicolumn{2}{|c|}{ 5.690940(7); 8.58811(1); 10.50960(1) } \\
\hline$\beta\left(^{\circ}\right)$ & \multicolumn{2}{|c|}{ 105.09130(10) } \\
\hline$V\left(\AA^{3}\right)$ & \multicolumn{2}{|c|}{ 495.936(1) } \\
\hline$Z$ & \multicolumn{2}{|c|}{2} \\
\hline Crystal system, Space group & \multicolumn{2}{|c|}{ Monoclinic, $\mathrm{Pn}$} \\
\hline Radiation type & $\mathrm{X}$-ray $(\lambda=0.58144 \AA)$ & Neutron $(\lambda=1.9605 \AA)$ \\
\hline Specimen & \multicolumn{2}{|c|}{ White powder } \\
\hline \multicolumn{3}{|l|}{ Data collection } \\
\hline Diffractometer & $\begin{array}{c}\text { Cristal beamline } \\
\text { (Soleil synchrotron) }\end{array}$ & $\begin{array}{c}\text { G44 beamline } \\
\text { (LLB Orphée reactor) }\end{array}$ \\
\hline Specimen mounting & $\varnothing=0.7$ mm capillary & $\varnothing=8$ mm V-container \\
\hline $2 \theta$ values $\left({ }^{\circ}\right)$ & $\begin{array}{c}2 \theta_{\min }=3.002^{\circ} \\
2 \theta_{\max }=49.996^{\circ} \\
2 \theta_{\text {step }}=0.002^{\circ} \\
294 \mathrm{~K}\end{array}$ & $\begin{array}{c}2 \theta_{\min }=6.01^{\circ} \\
2 \theta_{\max }=161.19^{\circ} \\
2 \theta_{\text {step }}=0.05^{\circ} \\
233 \mathrm{~K}\end{array}$ \\
\hline \multicolumn{3}{|l|}{ Refinement agreement factors } \\
\hline $\mathrm{Rp}$ & 0.0597 & 0.0370 \\
\hline Rwp & 0.0774 & 0.0497 \\
\hline Gof & 2.09 & 0.78 \\
\hline No. of data points & 23498 & 2962 \\
\hline \multicolumn{3}{|c|}{ Overall Refinement agreement factors } \\
\hline $\mathrm{Rp}$ & \multicolumn{2}{|c|}{0.0580} \\
\hline Rwp & \multicolumn{2}{|c|}{0.0765} \\
\hline Gof & \multicolumn{2}{|c|}{1.98} \\
\hline
\end{tabular}

Computer programs: Jana2006

The solved $\alpha$-canaphite structure presents molecular groups that correspond to pyrophosphate ions and four water molecules, as expected. The asymmetric unit has a composition corresponding to the formula $\mathrm{CaNa}_{2} \mathrm{P}_{2} \mathrm{O}_{7} \cdot 4 \mathrm{H}_{2} \mathrm{O}$, each atom occupying a $2 \mathrm{a}$ Wyckoff position of the Pn space group. The pyrophosphate molecule is thus non-centrosymmetric. Selected bond lengths and angles are reported in Table 3. The structure of the $\alpha$-canaphite is composed of alternating pyrophosphate and water layers (oriented according to the plane (001)) separated by layers of calcium and sodium cations (Figure 4). Hydrogen bonds ensure the cohesion of molecules within the layers (Figure 5). 
The P-O-P angle of the pyrophosphate group has often been discussed as an adaptive parameter in a number of structures. Its value can be determined from structural data $\left(129.9(3)^{\circ}\right.$ and $129.8^{\circ}$ as determined from both neutron/synchrotron X-ray diffraction data refinement and DFT calculations, respectively, Table 3) or from vibrational spectroscopic data as reported by Rulmont et al. ${ }^{33}$ and other workers ${ }^{34}$ with an empirical equation based on the relative position of symmetric and antisymmetric stretching vibrations of the POP group. Such a determination for $\alpha$-canaphite, $129^{\circ}{ }^{12}$ is in agreement with that obtained from the crystal structure. Torsions between the terminal groups are low, linking the canaphite structure to dichromate-type structures which is a common type of structure for hydrated calcium pyrophosphate compounds like triclinic calcium pyrophosphate dihydrate (t-CPPD), monoclinic calcium pyrophosphate tetrahydrate (m-CPPT $\beta$ ), anhydrous calcium pyrophosphate and also the anhydrous calcium disodium pyrophosphate $\alpha$ phase $\left(\alpha-\mathrm{CaNa}_{2} \mathrm{P}_{2} \mathrm{O}_{7}\right){ }^{29,35,36}$

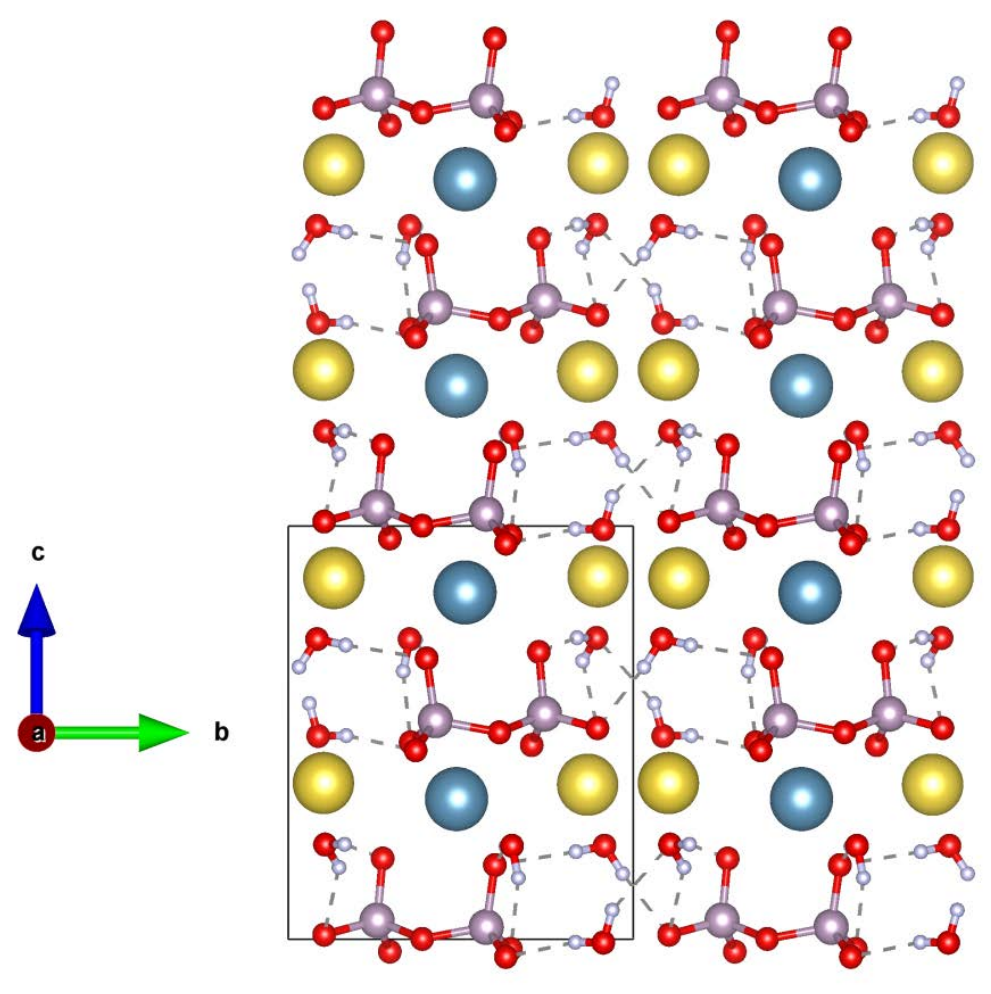

Figure 4. Three-dimensional representation of the monoclinic elemental cell of $\alpha$-canaphite, with placement of hydrogen atoms (obtained from refinement of both X-ray and neutron diffraction data), (yellow: sodium, blue: calcium, grey: phosphorus, red: oxygen, white: hydrogen) 


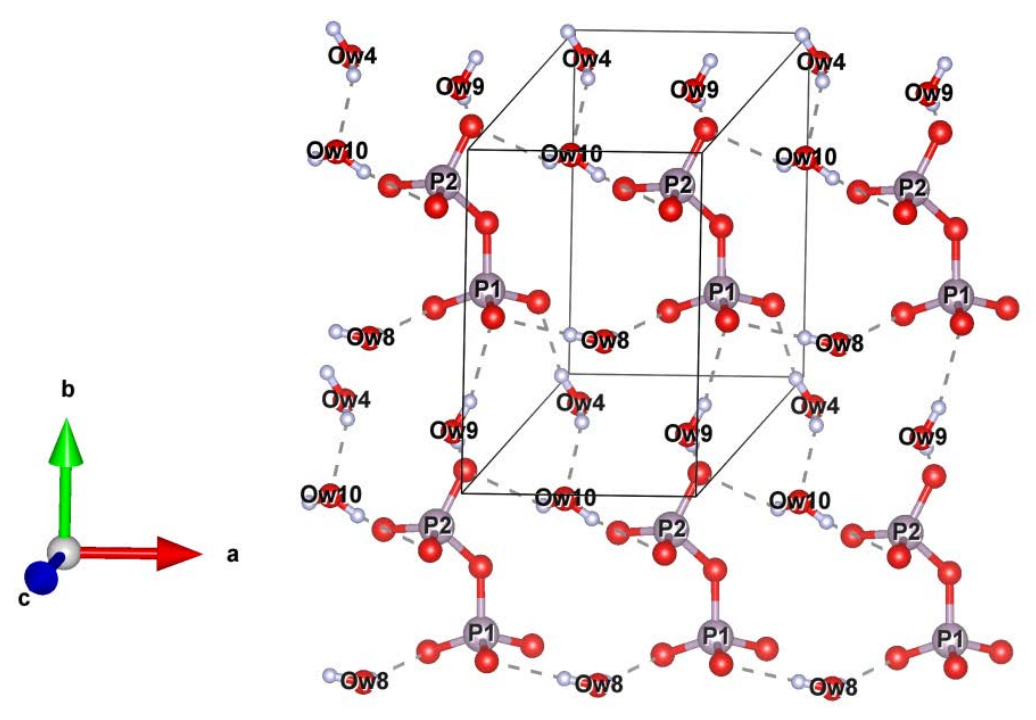

Figure 5. Representation of hydrogen bonds within the layers of the $\alpha$-canaphite. Ow: oxygen atoms of water molecules, (grey: phosphorus, red: oxygen, white: hydrogen, sodium and calcium cations are not represented in this figure).

Both calcium and sodium atoms are 6-fold coordinated. Calcium is mainly bound to pyrophosphate ions, with only one link to a water ligand through the "OW8” atom. On the contrary, Na1 and Na2 have 4 and 3 coordination bonds with water molecules, respectively. Polyhedra are linked together by one side. Sodium polyhedra are linked to each other and also to calcium polyhedra. Calcium polyhedra, on the other hand, are linked only to sodium polyhedra. These units are spaced from each other by pyrophosphate molecules (Figure 6). The cationic chains thus formed are staged, linking Na1-Ca1-Na2 blocks oriented along [120] and [120] axes. We can note also the different coordinations of Ow4, Ow9 and Ow10 atoms, only with sodium ions, and Ow8 with sodium-calcium binding (Figures 4 to 6).

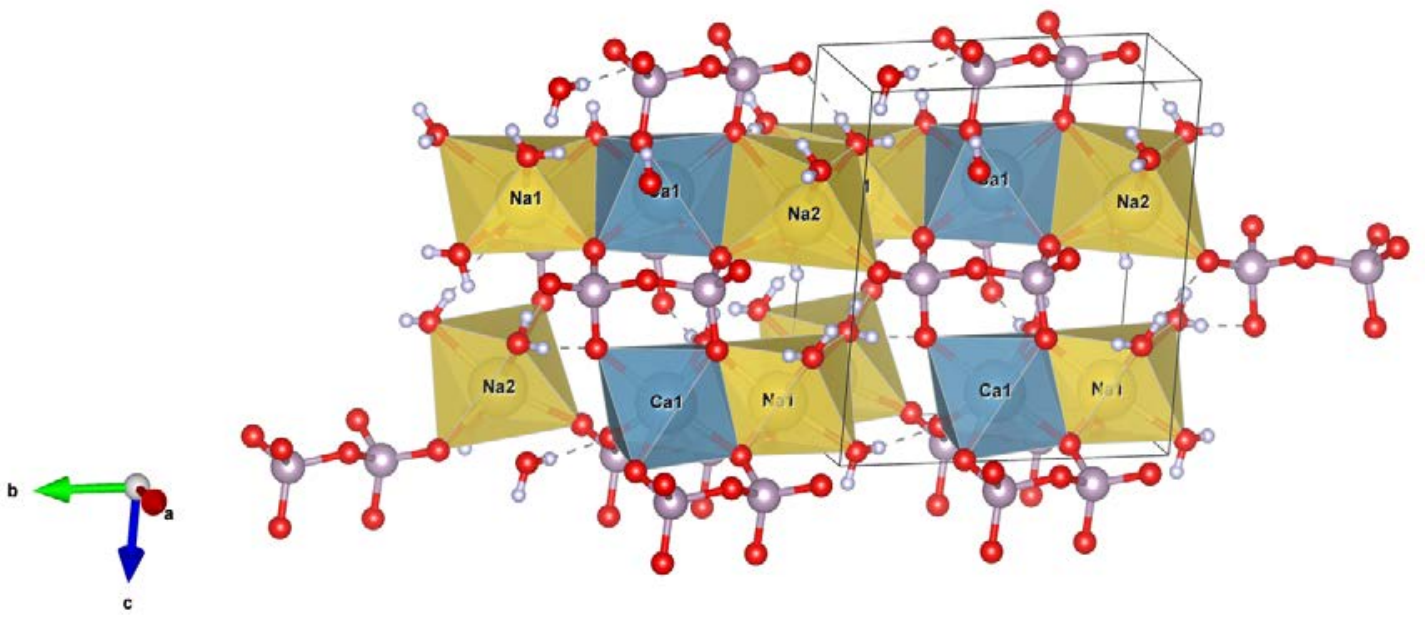

Figure 6. Representation of calcium and sodium polyhedra of the $\alpha$-canaphite structure (yellow: sodium, blue: calcium, grey: phosphorus, red: oxygen, white: hydrogen). 
As mentioned by Cheng et al. ${ }^{9}$, the $\alpha$ - and $\beta$-calcium disodium pyrophosphate tetrahydrate structures are very similar, the main differences being the organization of the $\mathrm{Ca}^{2+} \ldots \mathrm{P}_{2} \mathrm{O}_{7}{ }^{4-} \cdots \mathrm{Ca}^{2+}$ chains in relation to the plan (010). Figure 7 highlights the close relationship between the two structures, including the organization of the $\mathrm{CaNa}_{2} \mathrm{P}_{2} \mathrm{O}_{7} .4 \mathrm{H}_{2} \mathrm{O}$ units. The most significant differences can be observed on the alternating orientations of pyrophosphate molecules. The intra- and intermolecular distances (Table 3) are significantly similar to those of the $\beta$-canaphite structure. ${ }^{9}$

\section{a)}

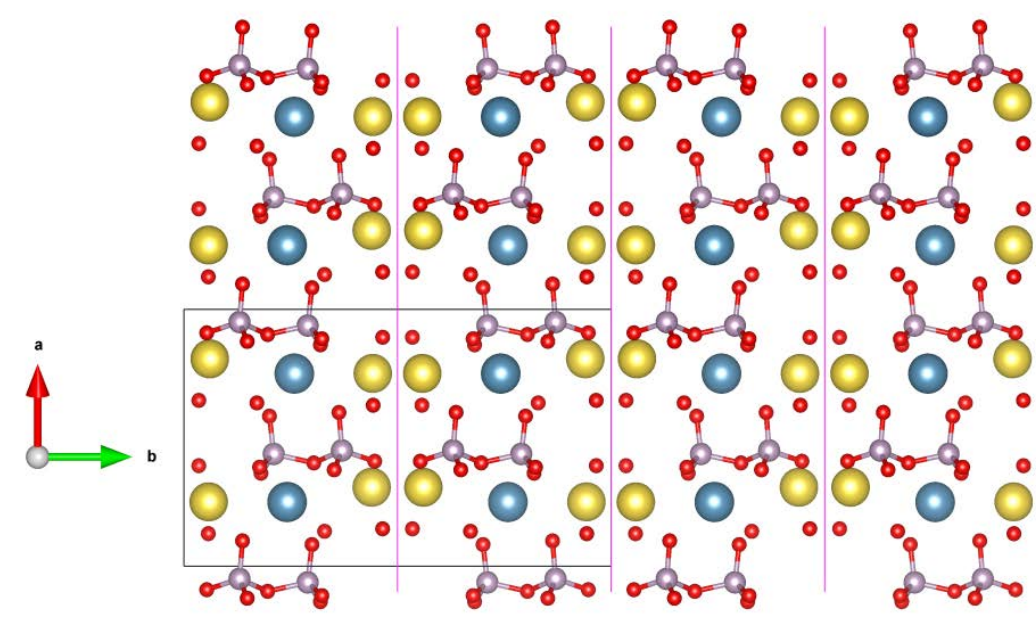

b)

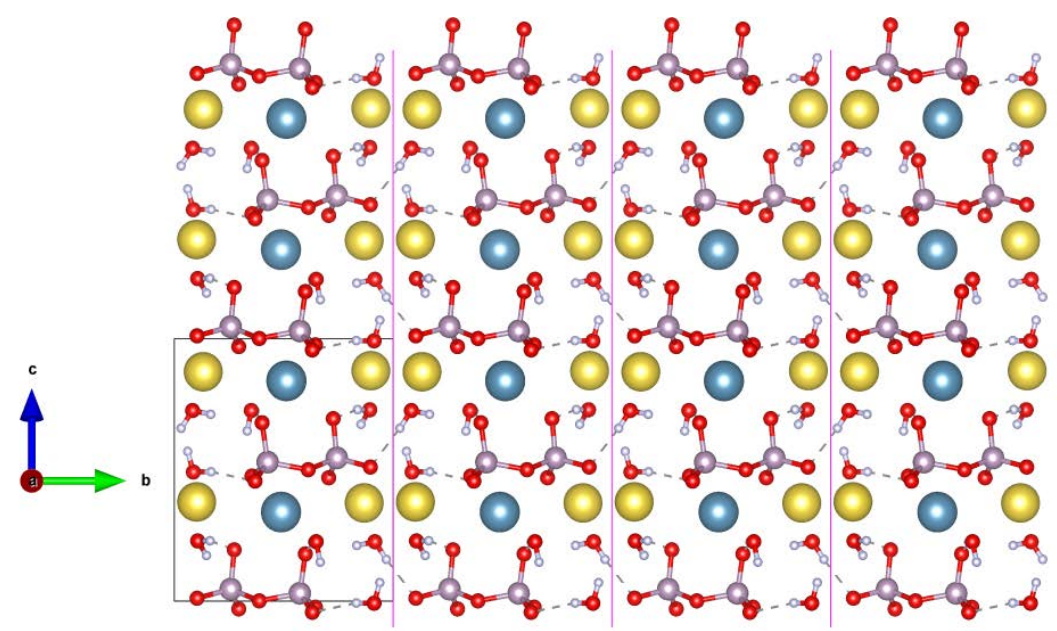

Figure 7. Comparison of $\beta$ (a) and $\alpha$ (b) canaphite structures, the (010) plans of interest are shown in blue, (yellow: sodium, blue: calcium, grey: phosphorus, red: oxygen, white: hydrogen). 
Table 3: Selected geometric parameters of the $\alpha$-canaphite structure $\left(\AA,^{\circ}\right)$. P-O, Ca-O and Na-O bond lengths $(\AA)$ (P1, P2, Ca1, Na1, Na2). Exp: data obtained from the refinement of both neutron/synchrotron X-ray diffraction data. Tot rel: data obtained after DFT relaxation of all positions, starting from Exp positions (see Materials \& Methods). O-P-O $\left(^{\circ}\right)$ angles, hydrogen bond lengths $(\AA)$ and angles $\left({ }^{\circ}\right)$ are given as well.

\begin{tabular}{|l|l|l|l|l|l|}
\hline \multicolumn{3}{|c|}{ P1 tetrahedron } & \multicolumn{3}{c|}{ P2 tetrahedron } \\
\hline & Exp & Tot rel & & Exp & Tot rel \\
\hline P1-O2 & $1.508(4)$ & 1.5324 & P2-O1 & $1.523(4)$ & 1.5299 \\
\hline P1-O5 & $1.542(3)$ & 1.5424 & P2-O3 & $1.536(4)$ & 1.5399 \\
\hline P1-O7 & $1.536(4)$ & 1.5232 & P2-O6 & $1.517(3)$ & 1.5247 \\
\hline P1-O11 & $1.620(4)$ & 1.6278 & P2-O11 & $1.631(4)$ & 1.6572 \\
\hline
\end{tabular}

\begin{tabular}{|l|l|l|l|l|l|l|l|l|}
\hline \multicolumn{3}{|c|}{ Ca1 octahedron } & \multicolumn{3}{c|}{ Na1 octahedron } & \multicolumn{3}{c|}{ Na2 octahedron } \\
\hline & Exp & Tot rel & & Exp & Tot rel & & Exp & Tot rel \\
\hline Ca1-O2 & $2.349(3)$ & 2.3397 & Na1-O1 & $2.448(5)$ & 2.447 & Na2-O1 & $2.407(4)$ & 2.399 \\
\hline Ca1-O3 & $2.347(4)$ & 2.3618 & Na1-Ow4 & $2.347(4)$ & 2.329 & Na2-O2 & $2.393(4)$ & 2.4239 \\
\hline Ca1-O5 & $2.357(4)$ & 2.3814 & Na1-O6 & $2.435(4)$ & 2.4499 & Na2-O3 & $2.755(4)$ & 2.7654 \\
\hline Ca1-O6 & $2.326(4)$ & 2.3321 & Na1-Ow8 & $2.416(4)$ & 2.3940 & Na2-Ow4 & $2.336(5)$ & 2.343 \\
\hline Ca1-O7 & $2.285(4)$ & 2.3009 & Na1-Ow9 & $2.421(5)$ & 2.4224 & Na2-Ow9 & $2.395(4)$ & 2.371 \\
\hline Ca1-Ow8 & $2.387(4)$ & 2.4376 & Na1-Ow10 & $2.749(5)$ & 2.675 & Na2-Ow10 & $2.377(5)$ & 2.4114 \\
\hline
\end{tabular}

\begin{tabular}{|l|l|l|l|l|l|l|l|}
\hline \multicolumn{3}{|c|}{ P1 tetrahedron } & \multicolumn{3}{c|}{ P2 tetrahedron } & \multicolumn{2}{c|}{ P1-O11-P2 } \\
\hline & Exp & Tot rel & & Exp & Tot rel & Exp & Tot rel \\
\hline O2-P1-O5 & $111.2(2)$ & 111.1 & O1-P2-O3 & $111.0(2)$ & 112.6 & $129.9(3)$ & 129.8 \\
\hline O2-P1-O7 & $112.7(2)$ & 113.3 & O1-P2-O6 & $115.7(2)$ & 115.2 & & \\
\hline O2-P1-O11 & $108.53(2)$ & 108.1 & O1-P2-O11 & $103.6(2)$ & 101.5 & & \\
\hline O5-P1-O7 & $111.24(2)$ & 112.0 & O3-P2-O6 & $112.7(2)$ & 112.4 & & \\
\hline O5-P1-O11 & $108.53(2)$ & 107.9 & O3-P2-O11 & $106.9(2)$ & 106.8 & & \\
\hline O7-P1-O11 & $104.3(2)$ & 103.8 & O6-P2-O11 & $106.0(2)$ & 107.2 & & \\
\hline
\end{tabular}

\begin{tabular}{|l|l|l|l|l|l|l|l|l|}
\hline \multicolumn{1}{|c|}{ D-H...A } & \multicolumn{2}{|c|}{ D-H } & \multicolumn{2}{c|}{ H...A } & \multicolumn{2}{c|}{ D---A } & \multicolumn{2}{c|}{ D-H...A $\left(^{\circ}\right)$} \\
\hline & Exp & Tot rel & Exp & Tot rel & Exp & Tot rel & Exp & Tot rel \\
\hline Ow4-H2-Ow10 & $0.83(1)$ & 0.977 & $2.20(2)$ & 2.02 & $2.945(5)$ & 2.912 & $150(2)$ & 150.8 \\
\hline Ow4-H3-O7 & $0.83(3)$ & 0.994 & $1.86(2)$ & 1.699 & $2.659(5)$ & 2.686 & $162(3)$ & 171.3 \\
\hline Ow8-H5-O5 & $0.83(2)$ & 0.999 & $1.96(1)$ & 1.717 & $2.772(5)$ & 2.712 & $167(3)$ & 172.8 \\
\hline Ow9-H6-O5 & $0.83(2)$ & 0.982 & $2.11(2)$ & 1.905 & $2.924(5)$ & 2.882 & $166(3)$ & 172.5 \\
\hline Ow10-H8-O3 & $0.83(2)$ & 0.996 & $2.05(3)$ & 1.802 & $2.861(6)$ & 2.786 & $167(3)$ & 168.9 \\
\hline Ow9-H11-O1 & $0.83(2)$ & 0.991 & $1.91(2)$ & 1.767 & $2.737(5)$ & 2.75 & $175(3)$ & 170.7 \\
\hline Ow8-H13-O2 & $0.83(2)$ & 0.984 & $2.25(2)$ & 2.022 & $3.000(5)$ & 2.969 & $151(3)$ & 160.9 \\
\hline
\end{tabular}

Complementarily, a methodology combining experimental (solid state NMR) and computational methods (first principles GIPAW calculations ${ }^{25}$ ) was implemented to characterize in detail the structure of $\alpha$-canaphite at the atomic level. The ${ }^{31} \mathrm{P},{ }^{1} \mathrm{H},{ }^{23} \mathrm{Na},{ }^{43} \mathrm{Ca}$ MAS NMR spectra and the corresponding 
extracted NMR parameters (isotropic chemical shifts, quadrupolar constants, $\mathrm{C}_{\mathrm{Q}}$, and quadrupolar asymmetries, $\eta_{\mathrm{Q}}$ ) are given in Figure 8 and Table 4, respectively.

It should be noted that calculations were performed on structural models deriving from the structure previously presented (Figures 4 to 6), in which either only $\mathrm{H}$ atom positions, or all atomic positions were relaxed by DFT. In the latter case, as discussed below, the agreement with experimental NMR data shows the best agreement. Therefore, P-O, Ca-O, Na-O and O-H bond lengths obtained after relaxation were added in Table 3. It appears that $\mathrm{P}$ tetrahedra and $\mathrm{Ca} / \mathrm{Na}$ octahedra geometries are not significantly modified by relaxation. On the other hand, Ow-H bond lengths originally around $0.83 \AA$ increase up to almost $1 \AA$ after relaxation, a value closer to what is usually expected in water. In parallel the $\mathrm{H}^{\cdots} \cdot \mathrm{Ow}$ distances decrease after relaxation since the $\mathrm{O} \cdots \mathrm{O}$ distances are maintained. Moreover, the global architecture of $\mathrm{H}$-bond network is not modified since $\mathrm{O}-\mathrm{H} \cdots \mathrm{O}$ angles do not change significantly.
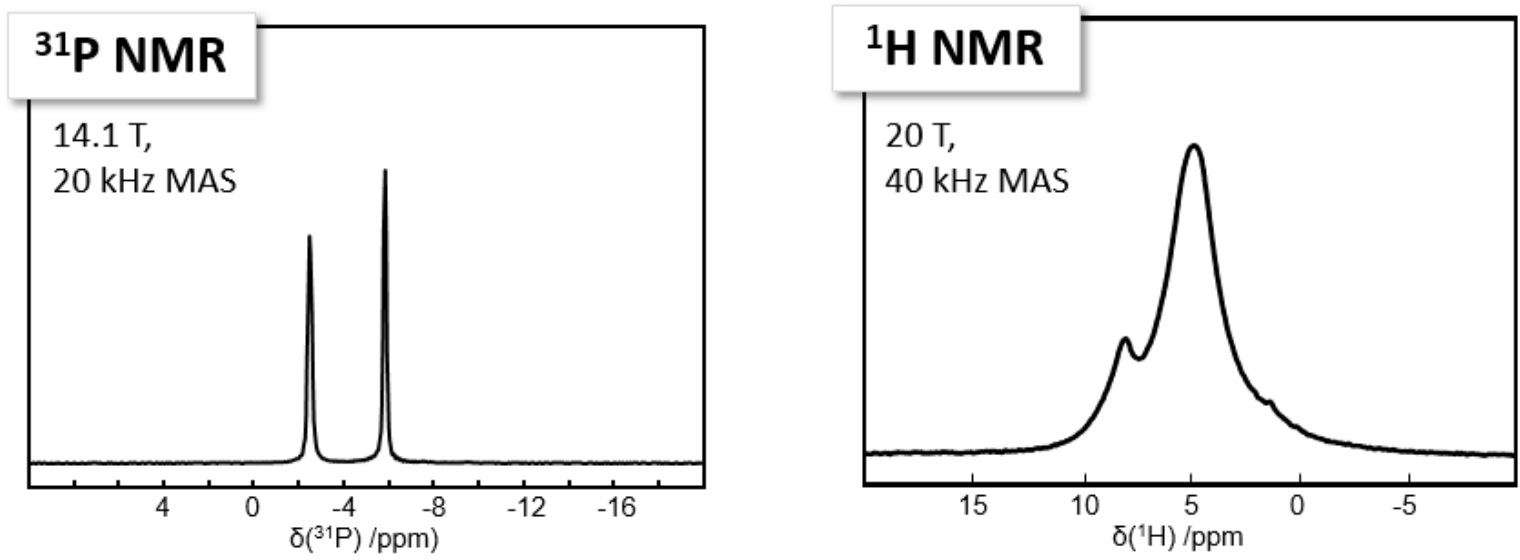

\section{${ }^{23} \mathrm{Na}$ NMR}

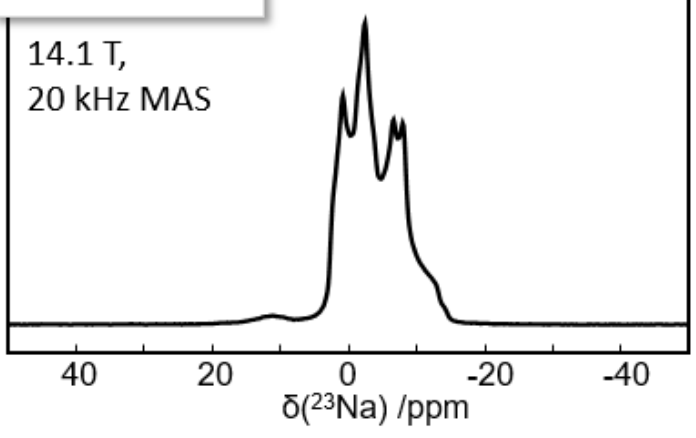

\section{${ }^{43} \mathrm{Ca}$ NMR}

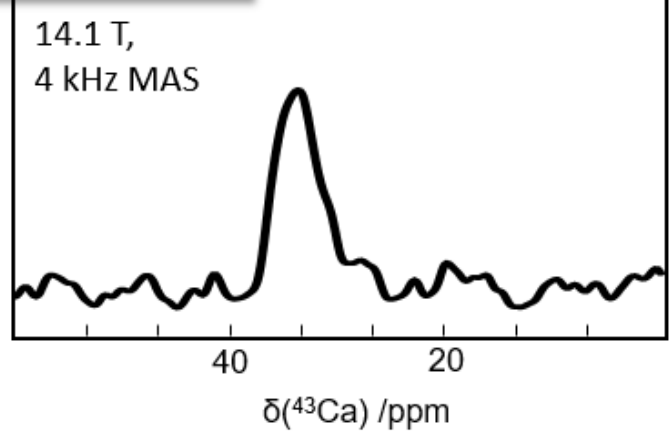

Figure 8. ${ }^{31} \mathrm{P},{ }^{23} \mathrm{Na},{ }^{43} \mathrm{Ca}$ MAS NMR spectra at $14.1 \mathrm{~T}$ and ${ }^{1} \mathrm{H}$ spin echo MAS NMR spectrum at $20.0 \mathrm{~T}$ of the as-synthesized $\alpha$-canaphite powder. All experimental details are given in the Materials and Methods section.

The ${ }^{31} \mathrm{P}$ MAS NMR spectrum is characterized by two distinct sharp isotropic peaks, in agreement with the presence of one unique pyrophosphate group (P1, P2) in the asymmetric unit. The high signal to noise ratio allows to conclude safely that potential impurities are completely absent. It follows that ${ }^{31} \mathrm{P}$ MAS NMR spectroscopy can act as a highly reliable tool of investigation to check the purity of a given $\alpha$-canaphite powder sample. The ${ }^{23} \mathrm{Na}$ MAS spectrum is more complex as ${ }^{23} \mathrm{Na}$ is a quadrupolar nucleus $(I=3 / 2)$. Nevertheless, it can be interpreted by the superposition of two contributions (Na1, Na2, see 
Table 4) broadened by residual second-order quadrupolar interaction (it is well established that MAS cannot suppress entirely such kind of second order broadening). Though less direct than ${ }^{31} \mathrm{P}$ MAS NMR analysis, ${ }^{23} \mathrm{Na}$ MAS NMR remains a complementary method to check the sample purity. The ${ }^{43} \mathrm{Ca}$ NMR spectrum exhibits a rather featureless peak corresponding to the unique calcium atom in the asymmetric unit. The broadening of the line is mainly due to residual second order quadrupolar effect as well, because calcium-43 is a spin 7/2 quadrupolar nucleus. Finally, the ${ }^{1} \mathrm{H}$ spin echo MAS NMR spectrum is probably the most difficult to interpret as residual ${ }^{1} \mathrm{H}-{ }^{1} \mathrm{H}$ homonuclear dipolar coupling broadens the line shapes (even spinning at $40 \mathrm{kHz}$ at the magic angle). The shifted ${ }^{1} \mathrm{H}$ resonance (above $6 \mathrm{ppm}$ ) is in agreement with the presence of some strong H-bonds within the canaphite structure.

Table 4: ${ }^{31} \mathrm{P},{ }^{23} \mathrm{Na},{ }^{43} \mathrm{Ca},{ }^{1} \mathrm{H}$ experimental and extracted data for the as-synthesized $\alpha$-canaphite powder. Computational details related to GIPAW calculations ${ }^{25}$ are given in the Materials and Methods section. Tot rel calc: GIPAW data obtained after DFT relaxation of all positions (see caption of Table 3). Rel H calc: GIPAW data obtained after DFT relaxation of $\mathrm{H}$ positions only.

\begin{tabular}{|c|c|c|c|c|c|c|c|c|c|}
\hline & \multicolumn{3}{|c|}{ Rel H calc } & \multicolumn{3}{|c|}{ Tot rel calc } & \multicolumn{3}{|c|}{ Experimental } \\
\hline & $\delta_{\text {iso }} / \mathrm{ppm}$ & $\mathrm{C}_{\mathrm{Q}} / \mathrm{MHz}$ & $\eta_{a}$ & $\delta_{\text {iso }} / \mathrm{ppm}$ & $\mathrm{C}_{\mathrm{Q}} / \mathrm{MHz}$ & $\eta_{Q}$ & $\delta_{\text {iso }} / \mathrm{ppm}$ & $\mathrm{C}_{\mathrm{Q}} / \mathrm{MHz}$ & $\eta_{a}$ \\
\hline P1 & -1.8 & & & -5.5 & & & $-5.8(0.1)$ & & \\
\hline P2 & 2.6 & & & -1.4 & & & $-2.5(0.1)$ & & \\
\hline & & & & & & & & & \\
\hline Na1 & 0.2 & -2.4 & 0.99 & 0.4 & 2.5 & 0.82 & $-0.3(0.1)$ & $2.20(0.05)$ & $0.78(0.02)$ \\
\hline $\mathrm{Na} 2$ & 4.6 & 2.0 & 0.44 & 3.3 & 2.1 & 0.50 & $4.0(0.1)$ & $2.00(0.05)$ & $0.30(0.02)$ \\
\hline Ca & 48.2 & -1.5 & 0.30 & 33.9 & -1.4 & 0.45 & & & \\
\hline & & & & & & & & & \\
\hline H2 & 3.3 & & & 3.7 & & & & & \\
\hline H3 & 7.8 & & & 7.6 & & & & & \\
\hline H4 & 2.1 & & & 2.3 & & & & & \\
\hline H5 & 7.8 & & & 8.5 & & & & & \\
\hline H6 & 4.3 & & & 4.8 & & & & & \\
\hline H8 & 6.5 & & & 7.3 & & & & & \\
\hline H11 & 7.2 & & & 6.5 & & & & & \\
\hline H13 & 5.2 & & & 5.1 & & & & & \\
\hline
\end{tabular}

GIPAW DFT calculations of the NMR parameters were performed on structural models deriving from the neutron/synchrotron X-ray structures, in which either only $\mathrm{H}$ atom positions, or all atomic positions were relaxed by DFT (Table 4). These calculations were found to be in very good agreement with the experimental data, confirming the accuracy of the final structure of $\alpha$-canaphite. In the case of ${ }^{31} \mathrm{P} N \mathrm{NR}$, results obtained after total relaxation of the $\alpha$-canaphite atomic positions led to improved agreement with experimental shifts. More importantly, for ${ }^{31} \mathrm{P}$ and ${ }^{23} \mathrm{Na}$, the GIPAW calculations could be used for assigning both sites resolved in NMR spectroscopy. Regarding ${ }^{1} \mathrm{H}$ NMR, the overall range of calculated ${ }^{1} \mathrm{H}$ chemical shifts was found to be in complete agreement with the corresponding experimental data 
shown in Figure 8. Moreover, as previously observed for other pyrophosphate phases, such GIPAW DFT calculations show the strong impact of H-bonding on the ${ }^{1} \mathrm{H}$ isotropic chemical shifts. ${ }^{13}$ If the positions of the protons are not precise enough, the GIPAW calculations usually diverge.

Vibrational spectroscopic analysis of the as-synthesized $\alpha$-canaphite phase (deuterated and nondeuterated).

$\alpha$-canaphite was characterized by FTIR and Raman spectroscopy as well. The vibrational spectrum of crystals can be interpreted using the factor group theory which predicts the number of lines expected and their activity in IR and Raman. Focusing on internal vibration modes of $\mathrm{H}_{2} \mathrm{O}\left(\mathrm{D}_{2} \mathrm{O}\right)$ and $\mathrm{P}_{2} \mathrm{O}_{7}{ }^{4-}$ molecular units, respectively 24 and 42 vibration lines should be expected (see details in supporting information on Vibrational spectroscopies and in Table S2 and Table S3). The Raman full spectrum of the as-synthesized $\alpha$-canaphite powder are presented in Figure S3 and the $\mathrm{H}_{2} \mathrm{O}\left(\mathrm{D}_{2} \mathrm{O}\right)$ and $\mathrm{P}_{2} \mathrm{O}_{7}{ }^{4-}$ molecular vibrational domains (FTIR and Raman) in Figure 9. The different FTIR and Raman lines and their respective assignments for $\alpha$-canaphite and its deuterated analogue are reported in Table S4. Obviously all the 66 lines predicted for the internal vibration modes cannot be distinguished, due to line broadening and superimpositions.

Generally several vibrational domains can be distinguished depending of the vibration energy. For $\mathrm{P}_{2} \mathrm{O}_{7}{ }^{4-}$ stretching vibrations (1200-700 $\mathrm{cm}^{-1}$ ), the two $\mathrm{PO}_{3}$ groups and the POP bridge are considered and their vibration domain is well identify (Figure 9a). In the 1200-1000 $\mathrm{cm}^{-1}$ range, the two $\mathrm{PO}_{3}$ groups of each pyrophosphate ion should show different lines (three for each group, distinguished as one symmetric and two antisymmetric vibrations), and the group factor effect could split again these lines. Generally one very strong $v_{\mathrm{s}}$ line is visible on the Raman spectrum of $\alpha$-canaphite and many other pyrophosphates salts. ${ }^{12,37}$ For the POP bridge two stretching modes, symmetric and antisymmetric, are found in the free ion (950-700 $\left.\mathrm{cm}^{-1}\right)$; in $\alpha$-canaphite these could also be split according to factor group considerations. In the spectra obtained only one $v_{\mathrm{s}}$ POP line is seen at the same position $\left(740-743 \mathrm{~cm}^{-1}\right)$ in Raman spectrum and the one of FTIR deuterated $\alpha$-canaphite, in the FTIR $\mathrm{H}_{2} \mathrm{O}$ canaphite spectrum this line seems hindered by the broad water libration line at this position. This line much intense in Raman than in IR, is a specific signature of pyrophosphate ions. A $v_{\text {as }}$ POP line is observed in all samples (FTIR and Raman) at 906-909 $\mathrm{cm}^{-1}$, in addition a stronger line is seen at $938-934 \mathrm{~cm}^{-1}$ only in FTIR, the attribution of which is not clear. Lower energy vibrations corresponding to bending modes of the $\mathrm{P}_{2} \mathrm{O}_{7}$ group are also present, but they seem more difficult to assign considering the other contributions, especially those of generally broad water libration lines. For $\mathrm{H}_{2} \mathrm{O}$ vibrations, the four water molecules in the formula unit show different environments and should exhibit 4 lines for each $v_{\mathrm{s}}, v_{\mathrm{as}}$ and $\delta$ vibration modes of the molecule (Figure 9b). These lines would also be split in virtue of group factor considerations. The Raman and FTIR lines (Figure 9) are in close positions according to the group theory treatment predicting identical irreducible representations, vibrational energy levels and transitions, for both techniques. This observation confirms the absence of inversion centre in the $\mathrm{P}_{2} \mathrm{O}_{7}{ }^{4-}$ groups as already noted from structural data. 
The deuteration allows to distinguish water bands from pyrophosphate ones especially in the bending domains where $\mathrm{H}_{2} \mathrm{O}$ libration lines can be easily shifted towards lower wavenumbers (Figure 9b). Such lines can be identified at about 800,706 , and $548 \mathrm{~cm}^{-1}$ especially. The observation of a faint line at 791 $\mathrm{cm}^{-1}$, in the deuterated sample FTIR spectrum, is attributed to an incomplete deuteration of the samples (about $20 \%$ of residual $\mathrm{H}_{2} \mathrm{O}$ ), possibly due to an exchange in air during sample preparation and analysis, Deuteration shifts the water lines to the low energy region (590, 520 and $410 \mathrm{~cm}^{-1}$ ) altering the observation of $\mathrm{P}_{2} \mathrm{O}_{7}{ }^{4-}$ ones especially in FTIR. The shift ratio between $\mathrm{H}_{2} \mathrm{O}$ and $\mathrm{D}_{2} \mathrm{O}$ lines, about 1.35, is in agreement with theoretical and experimental determinations. ${ }^{38}$ The FTIR and Raman determination of the POP angle using the Harcharras' diagram ${ }^{37}$ based on Lazarev observations is close to $129^{\circ}$ in agreement with the value obtained from diffraction data.

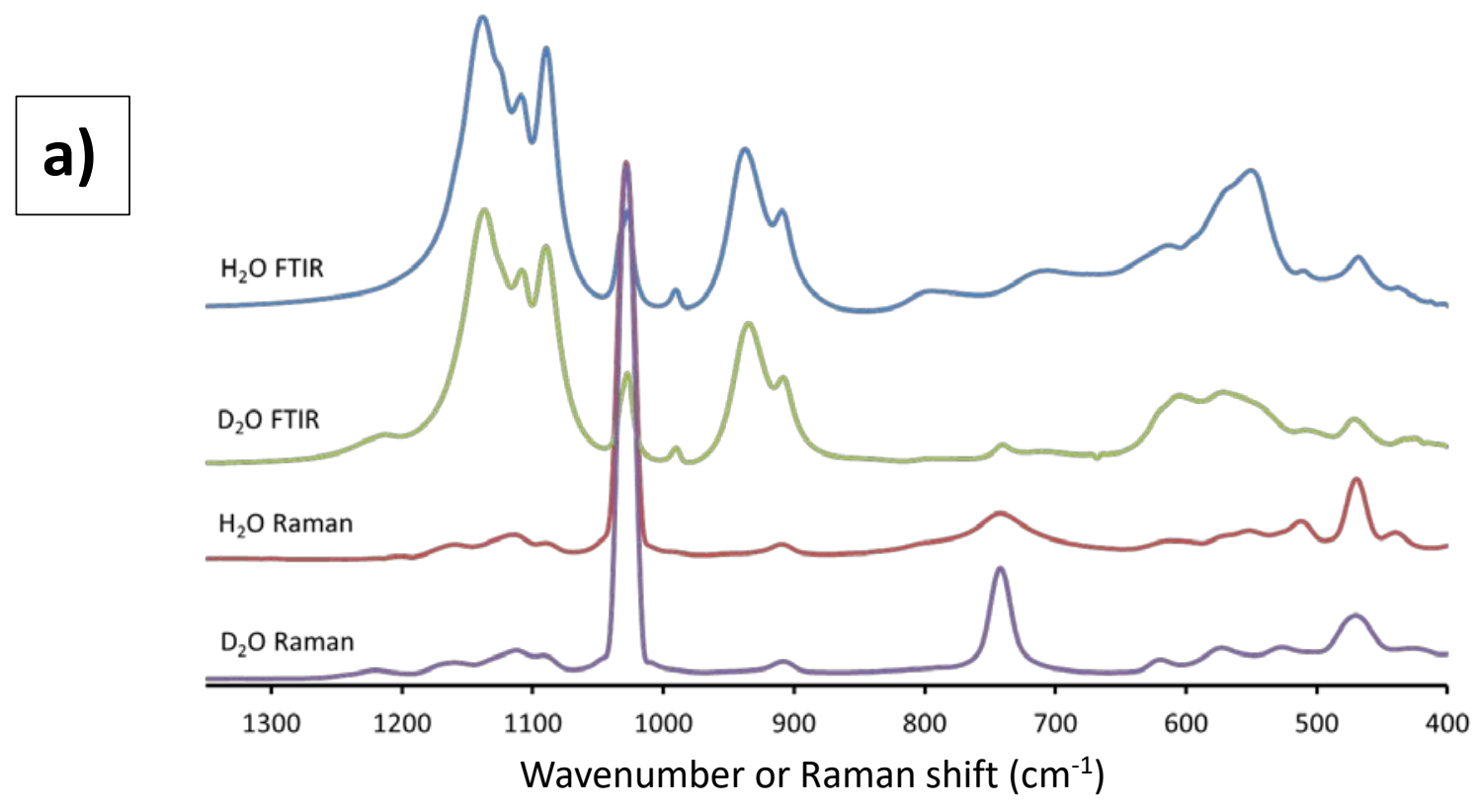

\section{b) $\mathrm{H}_{2} \mathrm{O}$ - $\alpha$-canaphite}

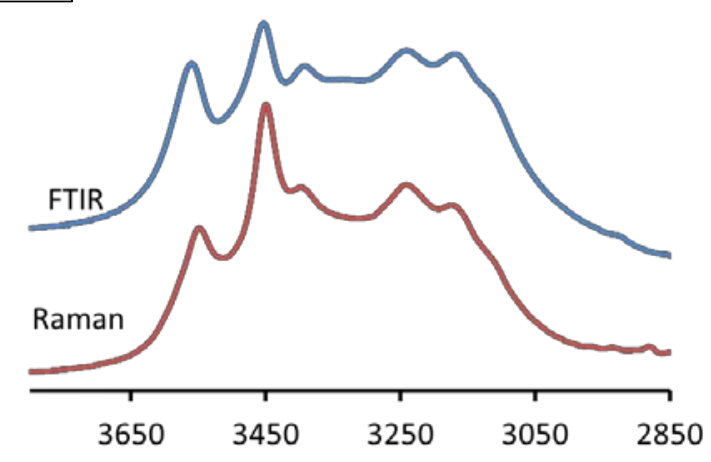

$D_{2}$ O- $\alpha$-canaphite

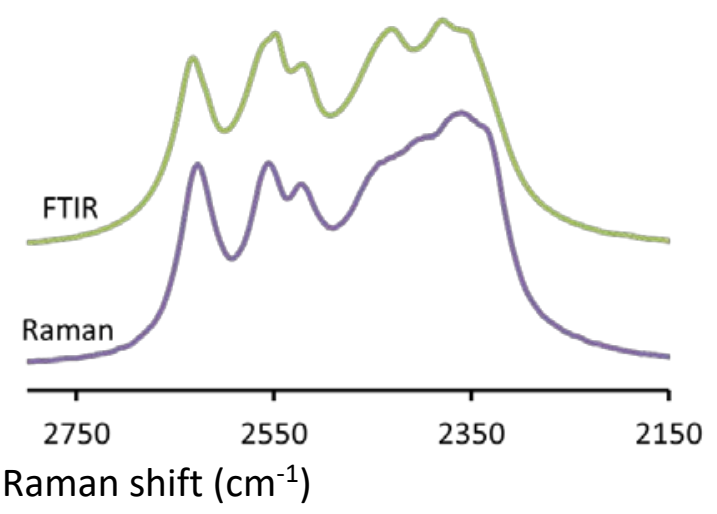

Figure 9. FTIR and Raman spectra of the synthesized $\alpha$-canaphite (deuterated and non-deuterated) showing the $\mathrm{PO}_{3}$ and $\mathrm{POP}$ group vibration domain (a) and the water vibration domain (b). 
We showed by thermogravimetric analysis that $\alpha$-canaphite recrystallized at about $440^{\circ} \mathrm{C}$ into the anhydrous calcium disodium pyrophosphate triclinic phase $\left(\alpha-\mathrm{CaNa}_{2} \mathrm{P}_{2} \mathrm{O}_{7}\right)$. The latter phase is not a layered structure (Figure S4) and the orientation of the pyrophosphate molecules are very different from that in the $\alpha$-canaphite structure for which strong hydrogen bonds are also involved as demonstrated by the present fine structural analysis by diffraction methods, solid state NMR and DFT calculations. These observations suggest that this transformation (recrystallization) is probably complex with strong structural reorganization. In addition, the observed dehydration mechanisms could be related to the different coordinations of Ow4, Ow9 and Ow10 atoms, only with sodium ions, and Ow8 with sodiumcalcium binding (Figures 4 to 6). Indeed the latter related water molecule (involving Ow8) could be the last one leaving the structure due to the two cations binding. This hypothesis is supported by the fact that one water molecule was also differentiated in another hydrated calcium pyrophosphate layered compound, monoclinic calcium pyrophosphate tetrahydrate beta (m-CPPT $\beta$ ), and identified as the last one to leave the structure upon heating and also the one involved in pyrophosphate internal hydrolysis into orthophosphate. ${ }^{34}$ In the case of $\alpha$-canaphite structure, we can hypothesize that the Ow8-related water molecule which is also the one the closer to pyrophosphate (distance Ow8-O11 = $3.123 \AA$ ) could be the one involved in the internal hydrolysis of pyrophosphate ions. Figure S5 showed the Raman spectrum of $\alpha$-canaphite dried at $250^{\circ} \mathrm{C}$, an intermediary temperature, i.e. higher than $37^{\circ} \mathrm{C}$ but lower than that leading to $\alpha$-canaphite full dehydration $\left(440^{\circ} \mathrm{C}\right)$ : we can observed the appearance of a new band of low intensity at $950 \mathrm{~cm}^{-1}$ characteristic of $\mathrm{v}_{\mathrm{s}} \mathrm{PO}_{4}$ supporting the hypothesis of the formation of orthophosphate via a pyrophosphate internal hydrolysis. Currently we are thoroughly investigating the effect of temperature on the $\alpha$-canaphite phase and especially its transformation up to the dehydrated phase $\left(\alpha-\mathrm{CaNa}_{2} \mathrm{P}_{2} \mathrm{O}_{7}\right)$ involving among others an hydrolysis of pyrophosphate ions upon moderate heating which could stabilize a potential intermediary amorphous phase formation; this study will be published in a forthcoming manuscript.

\section{Conclusion}

Canaphite is a layered phosphate of biological interest from the perspectives of in vivo calcium pyrophosphate-based crystals-associated disease or as an innovative bone substitute material based on enzyme- and/or pH-driven pyrophosphate $\left(\mathrm{P}_{2} \mathrm{O}_{7}{ }^{4-}\right)$ hydrolysis into orthophosphate $\left(\mathrm{PO}_{4}{ }^{3-}\right)$. The novel synthesis protocol developed here is simple, reproducible and enables pure $\alpha$-canaphite, $\mathrm{CaNa}_{2} \mathrm{P}_{2} \mathrm{O}_{7} .4 \mathrm{H}_{2} \mathrm{O}$ to be obtained. SEM allowed identifying the organization of $\alpha$-canaphite platelet crystals corresponding to a category 2 spherulite development and, TGA-DTA analysis, the dehydration of $\alpha$-canaphite into anhydrous calcium disodium pyrophosphate through a recrystallization process above $440^{\circ} \mathrm{C}$. Various observations of the phase development are presented. Most importantly for the first time, the monoclinic crystal structure of $\alpha$-canaphite was fully solved (including the positions of hydrogen atoms) by a combination of synchrotron X-ray and neutron diffraction data, solid state NMR 
and DFT calculations. This detailed structural analysis identifies the presence of some strong H-bonds within the $\alpha$-canaphite structure. One of the four oxygens from water molecules has a different coordination i.e. the two-cation binding of Ow8. It is therefore probable that this water is the last one to leave the structure during canaphite dehydration. In addition, the Ow8-related water molecule is most probably involved in the internal hydrolysis of pyrophosphate ions than the other three water molecules as it is the closest to pyrophosphate molecule. A thorough study is now necessary of the $\alpha$-canaphite dehydration process which will be fully described in a forthcoming paper. The very high signal-to-noise available from ${ }^{31} \mathrm{P}$ and ${ }^{23} \mathrm{Na}$ MAS NMR spectroscopies are suitable to confirm the purity of any sodium pyrophosphate precursor and $\alpha$-canaphite. ${ }^{31} \mathrm{P}$ MAS NMR provides much sharper spectral lines such that both $\mathrm{P}$ atoms of the unique pyrophosphate group in the asymmetric unit are completely resolved. The first principles GIPAW calculations provide unambiguous assignments both for ${ }^{31} \mathrm{P}$ and ${ }^{23} \mathrm{Na}$ resonance peaks and an interpretation for the scattering of the ${ }^{1} \mathrm{H}$ isotropic chemical shifts related to the H-bond network in the $\alpha$-canaphite structure. Finally, vibrational spectroscopies, especially Raman is a promising tool for fast in vitro, in vivo or ex vivo calcium disodium pyrophosphate microcrystals identification/diagnosis needing only a small amount of sample. This study provides a full description of $\alpha$-canaphite phase and some initial thermal property determination. Both are essential to fully exploit the structural and physico-chemical properties of $\alpha$-canaphite in materials science, especially for biomedical applications.

\section{Acknowledgments}

The authors would like to thank the Agence Nationale de la Recherche (PyVerres project - grant $n^{\circ}$ ANR-16-CE19-0013) for supporting this research work, Laboratoire Léon Brillouin and synchrotron Soleil for the provision of beamtimes (proposals $n^{\circ} 745$ and $n^{\circ} 20130932$, respectively). The $850 \mathrm{MHz}$ solid-state NMR Facility used in this research was funded by EPSRC and BBSRC, as well as the University of Warwick including via part funding through Birmingham Science City Advanced Materials Projects 1 and 2 supported by Advantage West Midlands (AWM) and the European Regional Development Fund (ERDF).. NMR spectroscopic calculations were performed using HPC resources from GENCI-IDRIS (Grant 097535).

\section{Author's contribution}

LM and MD carried out the synthesis and routine characterization of canaphite samples, NJ and MS the NMR experiments, CG the DFT calculations, FP the neutron diffraction analysis and the refinement of diffraction data, EE the synchrotron XRD analysis, PG the preliminary refinement of the diffraction data, CCH the laboratory XRD and TGA-DTA analyses, CR the vibrational spectroscopy analysis, DL and CB coordinated the NMR and DFT study and secured funding. JS coordinated the canaphite characterization and supervised LM and MD (PhD students). CCO was the scientific coordinator of the 
study and of the paper, supervised LM and MD (PhD students) and secure funding. All authors read, participated to correction and approved the final manuscript.

\section{Supporting information}

Tables: S1, S2, S3, S4

Figures: S1, S2, S3, S4, S5

\section{References}

1 D. R. Peacor, P. J. Dunn, W. B. Simmons and F. J. Wicks, Mineralogical Record, 1985, 16, 467468.

2 R. C. Rouse, D. R. Peacor and R. L. Freed, Am. Mineral., 1988, 73, 168-171.

3 K. P. Pritzker, In Calcium phosphates in Biological and Industrial Systems, ed. Z. Amjad, Kluwer Academic Publishers, 1998, pp. 277-301.

4 N. Khon, R. E. Hughes, D. J. McCarty and J. S. Faires, Ann Intern Med , 1962, 56, 738-45.

5 P. Richette, T. Bardin and M. Doherty, Rheumatology, 2009, 48, 711-715.

6 K. P. Pritzker, P. T. Cheng, S. A. Omar and S. C. Nyburg, J Rheumatol., 1981, 8, 451-455.

7 N. S. Mandel, G. S. Mandel, D. J. Carroll and P. B. Halverson, Arthritis Rheum., 1984, 27, 789796.

8 P. T. Cheng and K. P. H. Pritzker, Acta Crystallogr., 1980, B36, 921-924.

9 P. T. Cheng, S. C. Nyburg, M. E. Adams and K. P. H. Pritzker, Cryst Struct. Comm., 1979, 8, 313317.

10 M. R. Cave, Investigation of layered calcium phosphates and related materials for biomaterial applications, PhD thesis, 2010, University of Birmingham, United Kingdom.

11 T. V. Safronova, V. I. Putljaev, P. A. Sechejko and J. D. Tret'jakov, Russian patent nRU2499767C1, 2012.

12 I. Hubert Joe, G. Aruldbas and G. Keresztury, J. Raman Spectrosc., 1991, 22, 537-539.

13 P. Gras, A. Baker, C. Combes, C. Rey, S. Sarda, A. J. Wright, M. E. Smith, J. V. Hanna, C. Gervais, D. Laurencin and C. Bonhomme, Acta Biomater, 2016, 31, 348-357.

14 C. Slater, D. Laurencin, V. Burnell, M. E. Smith, L. M. Grover, J. A. Hriljac and A. J. Wright, J. Mater. Chem., 2011, 21, 18783-18791.

15 A.P. Legrand, H. Sfihi, N. Lequeux and J. Lemaître, J. Biomed. Mater. Res. B: Appl. Biomater., 2009, 91, 46-54.

16 Y. Yu, H. Guo, M. Pujari-Palmer, B. Stevensson, J. Grins, H. Engqvist and M. Edén, Ceramics International, 2019, 45, 20642-20655.

17 L. Mayen, N. D. Jensen, D. Laurencin, O. Marsan, C. Bonhomme, C. Gervais, M. E. Smith, C. Coelho, G. Laurent, J. Trebosc, Z. Gan, K. Chen, C. Rey, C. Combes and J. Soulié, Acta Biomaterialia, 2020 (in press). 
K. Momma and F. J. Izumi, Appl. Crystallogr., 2011, 44, 1272-1276.

G. Kresse and J. Hafner, Phys. Rev. B, 1994, 49, 14251.

20 P. Giannozzi, S. Baroni, N. Bonini, M. Calandra, R. Car, C. Cavazzoni, D. Ceresoli, G. L. Chiarotti, M. Cococcioni, I. Dabo, A. Dal Corso, S. de Gironcoli, S. Fabris, G. Fratesi, R. Gebauer, U. Gerstmann, C. Gougoussis, A. Kokalj, M. Lazzeri, L. Martin-Samos, N. Marzari, F. Mauri, R. Mazzarello, S. Paolini, A. Pasquarello, L. Paulatto, C. Sbraccia, S. Scandolo, G. Sclauzero, A. P. Seitsonen, A. Smogunov, P. Umari and R. M. Wentzcovitch, J. Phys. Cond. Matt., 2009, 21, 395502.

21 S. Baroni, S. de Gironcoli, A. Dal Corso and P. Giannozzi, Rev. Mod. Phys., 2001, 73, 515-562.

22 J. P. Perdew, K. Burke and M. Ernzerhof, Phys. Rev. Lett., 1996, 77, 3865-3868.

23 N. Troullier and J. L. Martins, Phys. Rev. B, 1991, 43, 1993-2006.

24 L. Kleinman and D. Bylander, Phys. Rev. Lett., 1982, 48, 1425-1428.

25 C. Pickard and F. Mauri, Phys. Rev. B, 2001, 63, 245101.

26 K. Lejaeghere, G. Bihlmayer, T. Björkman, P. Blaha, S. Blügel, V. Blum, D. Caliste, I. E. Castelli, S. J. Clark, A. Dal Corso, S. de Gironcoli, T. Deutsch, J. Kay Dewhurst, I. Di Marco, C. Draxl, M. Dułak, O. Eriksson, J. A. Flores-Livas, K. F. Garrity, L. Genovese, P. Giannozzi, M. Giantomassi, S. Goedecker, X. Gonze, O. Grånäs, E. K. U. Gross, A. Gulans, F. Gygi, D. R. Hamann, P. J. Hasnip, N. A. W. Holzwarth, D. Iuşan, D. B. Jochym, F. Jollet, D. Jones, G. Kresse, K. Koepernik, E. Küçükbenli, Y. O. Kvashnin, I. L. M. Locht, S. Lubeck, M. Marsman, N. Marzari, U. Nitzsche, L. Nordström, T. Ozaki, L. Paulatto, C. J. Pickard, W. Poelmans, M. I. J. Probert, K. Refson, M. Richter, G-M Rignanese, S. Saha, M. Scheffler, M. Schlipf, K. Schwarz, S. Sharma, F. Tavazza, P. Thunström, A. Tkatchenko, M. Torrent, D. Vanderbilt, M. J. van Setten, V. Van Speybroeck1, J. M. Wills, J. R. Yates, G-X Zhang and S. Cottenier, Science, 2016, 351, aad3000.

27 C. Gervais, D. Laurencin, A. Wong, F. Pourpoint, J. Labram, B. Woodward, A. P. Howes, K. J. Pike, R. Dupree, F. Mauri, C. Bonhomme and M. E. Smith, Chem Phys Lett , 2008, 464, 42-48.

28 P. Pyykkö, Mol. Phys., 2008, 106, 1965.

29 K. M. N. Burgess, Y. Xu, M. C. Leclerc and D. L. Bryce, Inorg. Chem., 2014, 53, 552-561.

30 J. Bennazha, A. Boukhari and E. M. Holt, Solid State Sci., 1999, 1, 373-380.

31 L. Granasy, T. Pusztai, G. Tegze, J. Warren and J. Douglas, Phys Rev, 2005, E72, 011605.

32 P. Gras, Etude physico-chimique et structurale de pyrophosphates de calcium hydratés: application aux micro-calcifications associées à l'arthrose, PhD thesis, 2014, Université de Toulouse, France.

33 A. Rulmont, R. Cahay, M. Liegeois-Duyckaerts and P. Tarte, Eur J Solid State Inorg Chem, 28, 207-219.

34 P. Gras, C. Rey, O. Marsan, S. Sarda and C. Combes, Eur. J. Inorg. Chem., 2013, 34, 5886-5895.

35 T. Balić-Žunić, M. R. Christoffersen and J. Christoffersen, Acta Crystallogr., 2000, B56, 953-958.

36 N. L. Davis, G. S. Mandel, N. S. Mandel and R. E. Dickerson, J. Crystallogr. Spectrosc. Res., 1985, 15, 513-521.

37 M. Harcharras, A. Ennaciri, A. Rulmont and G. Gilbert, Spectrochemica Acta Part A, 1997, 53, 345-352.

38 F.W. Poulsen, J. Raman Spect., 1986, 17, 189-191. 